February, 2000

\title{
How to Set Minimum Acceptable Bids, with an Application to Real Estate Auctions
}

by

\author{
R. Preston McAfee, \\ Daniel C. Quan, \\ and
}

Daniel R. Vincent*

\begin{abstract}
In a general auction model with affiliated signals, common components to valuations and endogenous entry, we compute the equilibrium bidding strategies and outcomes, and derive a lower bound on the optimal reserve price. This lower bound can be computed using data on past auction combined with information about the subsequent sales prices of unsold goods. We compute the lower bound using data from FDIC real estate auctions. We find the point estimate for an upper bound on the optimal reserve for real estate to be $75 \%$ of appraised value. Using data from private real estate auctions, we show that when reserve prices are around $50 \%$ of appraised value, seller revenues are increasing in the reserve price.
\end{abstract}

* Department of Economics, University of Texas; Financial Management Dept., Cornell University; and Department of Economics, University of Maryland, respectively. We thank Susan Athey, Dennis Epple, Sridhar Moorthy, David Reiley and Richard Zeckhauser for useful comments. We are indebted to two 
anonymous referees for extensive comments. Finally, we appreciate the Federal Deposit Insurance Corporation's provision of most of the data. 
There are many situations in which a seller, often a government, auctions many similar items over a long period of time. For example, over the past several decades, the Federal Deposit Insurance Corporation (FDIC) and the Resolution Trust Corporation (RTC) have auctioned tens of thousands of houses for tens of billions of dollars. Over the past thirty years, the U.S. Department of the Interior has auctioned billions of dollars worth of timber cutting rights and off-shore oil leases. Sales of treasury bills are in the trillions of dollars. This paper provides a procedure for increasing the seller's revenue over that obtained by ad hoc formulae used in practice by using historical data to improve on the minimum acceptable bid, or reserve price, imposed in the auction. We apply the procedure to data from six separate real estate auctions and find a lower bound for the optimal reserve price for these property of $75 \%$ of appraised value, significantly more than reserve prices often used in practice. Because the procedure is applicable to environments of considerable economic value, including not only real estate but also oil and other mineral rights, timber, radio spectrum and treasury bills, there is a potential for application of our theory to create a significant amount of increased revenue.

In contrast to much of the literature, we study an environment which allows for affiliation in the signals and common components to value, and in which participation is endogenously determined. With some important exceptions, the empirical auction literature has concentrated on the independent private values environment in which bidders know their own valuations and these valuations are independently distributed. ${ }^{1}$ Such models cannot account for either correlation in valuations, as would occur if there are common factors that influence value and vary from auction to auction, or in unobserved factors affecting valuations that are common to the bidders. ${ }^{2}$ These factors are clearly important in any real world auction environment, as Paul

\footnotetext{
${ }^{1}$ The most important theoretical treatment is Paul Milgrom and Robert Weber (1982), which developed the mathematical tools used in the present study. The auction literature is surveyed in McAfee and John McMillan (1987a). More specialized surveys are provided by Milgrom (1988) and Robert Wilson (1991). Optimal auctions with correlated values were studied by Jacques Cremer and Richard McLean (1985), McAfee, McMillan, and Philip Reny (1989), and McAfee and Reny (1991).

${ }^{2}$ Even if bidders know their own value for the item being sold, it would be rather surprising if these values weren't correlated through unobserved factors. For example, the desirability of a work of art purchased purely for private viewing is likely to be correlated across bidders. More generally, bidders only receive an estimate of the value, and the realized value will depend on unobserved factors correlated with all of the bidders' signals; e.g. the amount of oil in a tract is unobserved prior to drilling, but is presumably correlated with all the bidders' signals. In addition, the potential for resale at an uncertain future price induces correlation in the bidders' valuations.
} 
Milgrom and Robert Weber (1982) persuasively argue. In addition, the auction literature has focused on the case of an exogenous set of bidders. In many real situations, bidders are attracted to the auction by potential profits, and changes in the selling mechanism will change the bidders' participation decisions.

In all but the simplest environments, optimal selling mechanisms tend to be extraordinarily complicated and depend on the distributions of signals, utility functions and other aspects of the environment that are not actually observable but assumed known in order to fully specify a model. While we will also assume that agents in the model know the distributions of signals and utility functions of the other agents, in contrast to the existing literature, we simply derive a lower bound on the optimal reserve price that does not depend on specific knowledge of the distributions or utility functions posited in the model. ${ }^{3}$ That is, the lower bound will be distribution-free. ${ }^{4}$ We consider this approach to be an improvement over the optimal auctions approach because our approach is more likely to be robust to failures in the assumptions, as our approach depends on fewer assumptions and less knowledge on the part of the seller. In addition, by focusing on a simple improvement that a seller might reasonably adopt, rather than a complex optimal auction, our approach is more practical.

Consider a sequence of similar items sold by auction. These items could be houses, off-shore oil rights, or other related items. We consider how to use data from early auctions to adjust the reserve price for the later sales. We presume that items that fail to sell have realized values prior to the subsequent auctions of new items. For example, items that fail to sell in early auctions may also be sold at auction or by bargaining or by any other means. In particular, in the real estate sales application, houses that failed to sell in early auctions

\footnotetext{
${ }^{3}$ The present study is an extension of the results presented in McAfee and Vincent (1992), which applied a related analysis to the case of off-shore oil auctions. The present study allows for more general valuation functions, and does not depend on observation of the $e x$ post value of the object. In many cases, observation of the ex post value of sold objects will be impossible; the OCS oil lease auction data, studied by Kenneth Hendricks and Robert Porter, with coauthors (1987, 1990, 1992), is an exception in this regard. Perhaps most importantly, the present study computes improvements for potentially large adjustments to the reserve, while the previous study applied only to small changes. In addition to our earlier study, McAfee and McMillan (1987b,c), Harstad (1990) and Levin and Smith (1994) examine endogenous and stochastic participation in auctions.

${ }^{4}$ Distributions and utility functions are the primitives of auction theory and we follow the literature in assuming that these primitives are common knowledge of the bidders. Our constructed lower bound is observable in many auction data sets. In contrast, setting an optimal reserve price in an independent private values auction requires knowledge of the distribution of valuations.
} 
were sold later by bargaining or subsequent auctions, and a price for the government realized. This later realized price, discounted to the time of the initial sale attempt, comprises the data for the adjustment of the reserve for subsequent auction of new items.

We show that the discounted expected sale price of items that failed to sell in past auctions is a lower bound for the optimal reserve, provided this average sale price exceeds the past reserve. It is useful to distinguish ex ante considerations of the seller, which occur prior to the participation decisions, from ex post considerations, which occur at the time of bidding. Endogenous participation implies that the bidders earn zero ex ante expected rents. Thus, on average, the entire gains from trade accrue to the seller, and in contrast to models with an exogenous number of bidders, the seller wishes to post an ex ante efficient reserve price. However, efficiency ex post means setting a reserve price equal to the seller's value associated with retaining the object. For a large class of environments, the ex ante efficient reserve exceeds the ex post efficient reserve, because of an entry externality. Therefore, the seller ex ante should post a reserve price above the seller's opportunity cost of sale.

Two complications arise in calculating the value of the object to the seller. First, the ex post efficient reserve holds the participation strategy of the bidders constant, and equates the value of items that just fail to sell at the current reserve to the seller's expected value of these items, ${ }^{5}$ rather than the average value of all unsold items. Realistically, though, it is the average value that is typically observable. Second, even the average value of unsold items will tend to vary with the reserve. If unsold goods are kept by the seller and used in some alternative capacity of known value, then the seller could simply observe the value of unsold goods. However, more plausibly, the value of the item depends on some imperfectly observed intrinsic quality. This is particularly the case when the opportunity cost of sale in the present auction is the value of sale in a subsequent auction. This quality will tend to be correlated with buyers' willingness to pay, and thus changing

\footnotetext{
${ }^{5}$ That is, the ex post efficient reserve, $r$, must satisfy the condition that it equal the seller's value of items that fail to sell at a reserve $r$ but would sell at any reserve $r-\varepsilon$ for small $\varepsilon>0$, since this equates the seller's value of selling and not selling at the margin. We will refer to this value as the value of marginal items.
} 
the reserve price will change the quality, and hence the expected value to the seller, of unsold items. Therefore, changes in the reserve price change the composition of the set of objects that fail to sell, a classic case of sample selection bias.

The sample selection problem implies that the present discounted expected value of unsold items is a lower bound on the appropriate reserve price. Suppose that the current reserve price is less than the average resale value of objects that fail to sell in the current auction. Then the value of marginal objects that fail to sell at the current reserve exceeds the average value of objects that fail to sell, which by assumption exceeded the reserve. Thus, whenever the average present value of future resale exceeds the reserve price, the reserve price should be raised to at least this average value. ${ }^{6}$

We apply this theory to auctions of real estate in 1997.While reserve prices were officially kept secret for most real estate auctions, there is substantial evidence that the reserve was less than $75 \%$ of appraised value, and in some cases reserve prices are less than $50 \%$. We find that the appropriate reserve is at least $75 \%$ of appraised value, indicating that the government is selling houses with too low a reserve. ${ }^{7}$ In particular, we conclude that plans for the RTC to lower reserve prices to $60 \%$, or even $50 \%$, of appraised value are misguided. ${ }^{8}$

Our evaluation of the profitability of raising reserve prices depends on the theory being an accurate description of the actual environment. To assess this issue, we collected data on auctions conducted in the early

\footnotetext{
${ }^{6}$ Raising the reserve will, of course, increase the value of the marginal good that fails to sell. Thus, raising the reserve to the average value will result in a reserve that is still too low.

${ }^{7}$ We have not considered management expenses involved in resale in computing this outcome, although we did account for foregone interest. The expenses involved in resale would tend to lower our estimate of the optimal reserve price. According to the Wall Street Journal, May 30, 1991, p.1, "The costs of carrying seized property - including fire and liability insurance, general upkeep, repairs from vandalism, capital improvements, property taxes, legal fees, and, most significantly, the immobilization of otherwise unproductive assets can run $20 \%$ of the property's appraised value annually." According to Douglas Hodge, a broker and property manager who has represented the FDIC, a more reasonable figure for maintenance and auction commission charges is $4 \%$ to $6 \%$. Taking this number as accurate we would find an appropriate reserve of about $70 \%$ for buildings.

${ }^{8}$ According to the New York Times, March 26, 1991, p. D1: "Under the plan, Resolution Trust will be able to immediately mark down the price of real estate by $20 \%$ of appraised value, $40 \%$ after 6 months and $50 \%$ after 18 months. Existing regulations require periodic appraisals and permit the regulators to mark down the prices of property immediately by only 5 to 10 percent, 15 percent after six months, and then 20 percent after 9 months."
} 
1990's with published reserve prices held by a bank. We find that in the neighborhood of reserve prices at about $50 \%$ of appraised value, increasing reserve prices increases expected revenue. An alternative explanation for the effect of higher reserves on final sale prices is that the reserves reflect corrections to errors in appraisals - higher reserves are posted when it is observable to the seller and buyers that the property is worth more than its appraisal. However, were this alternative explanation true, the properties with high reserves would be as likely to sell as properties with low reserves. In fact, higher reserves are associated with higher probabilities of failing to sell, supporting the conclusion that the reserve price is inefficiently low.

\section{The Affiliated Values Model with Endogenous Entry: Bidder Behavior}

We assume that there is a large number, $n$, of potential bidders, sufficiently large so that even without a posted reserve, it is not an equilibrium for all bidders to bid. For a cost $s$, each bidder $i$ can obtain a signal $x_{i}$ which is a realization of the random variable $X_{i}$ with cumulative distribution function $F\left(X_{i} \mid \theta\right)$, where $\theta$ is a vector of variables not observed by any agent. Bidders who do not pay $s$ are assumed not to bid, perhaps because they do not learn about the existence of the auction without paying $s$. We call $\theta$ the common component. In applications, $\theta$ represents all aspects of the item for sale that affect the value of the item but are not observed by the agents. By convention, higher values of $\theta$ correspond to higher values of the good. Bidders' signals are independently distributed, conditional on $\theta$. We also assume that $X_{i}$ has a smooth density $f\left(X_{i} \mid \theta\right)$. The value of the good to the buyer, given realized signal $x$ and common component $\theta$, is $u(x, \theta)$. The payoff $u$ is assumed to be nondecreasing in all of its arguments.

This model is less general than Milgrom and Weber's (1982) model in two respects. First, Milgrom and Weber do not assume the signals are conditionally independent. Second, other buyers' signals do not enter into the payoff $u$ of a given buyer $i$. We assume, following Milgrom and Weber, that each of the random 
variables, $X_{1}, \ldots, X_{n}$ are affiliated with the common component, $\theta \cdot{ }^{9}$ As is standard, $u, f, s, n$ and the distribution of $\theta$ are common knowledge among the potential buyers.

The model is usefully illustrated by considering the sale of a house. The variables $\theta$ represent all of the unobservable attributes of the house, measured so that higher values of $\theta$ represent higher quality. Potential buyers decide whether to examine the property; those that conduct an examination incur a cost $s$. Each buyer forms an estimate of the value of the property, denoted $x$, which is a sufficient statistic for everything observable about the house, from the color of the appliances to the sagging roof. ${ }^{10}$ Armed with the estimate $x$, buyers submit bids in an auction. The seller's value of the house if the house fails to sell is denoted $\sigma$.

The seller holds an auction with reserve price $r$. The auction form may be any of a first or second price auction or oral ascending bid auction. In such auctions bidders will not participate unless their signal is sufficiently high, at a level Milgrom and Weber (1982) call the screening level, which we denote by $x_{r}$. The screening level is the signal such that, knowing that all other bidders either didn't participate or observed signals less that $x_{r}$ (and hence didn't submit bids), a buyer with signal equal to $x_{r}$ just breaks even by paying $r$ for the good.

The timing is as follows. First, the seller announces $r$. Second, the buyers choose whether or not to pay a cost $s$ to acquire a signal. Only the symmetric random participation equilibrium will be considered, in which buyers choose to acquire a signal with probability $\rho \in(0,1) .{ }^{11}$ Third, informed buyers submit bids; bids

\footnotetext{
${ }^{9}$ For two random variables, affiliation is also known as the Monotone Likelihood Ratio Property. For general functions as well as densities, affiliation is called log supermodularity. A twice differentiable function $f$ is supermodular if the cross-partials are non-negative. $f$ is $\log$ supermodular if $\log (f)$ is supermodular. See Milgrom and Roberts (1990) for an exhaustive set of consequences of supermodularity. Affiliation may be thought of as a strong form of local positive correlation - that is, two random variables are affiliated if and only if increasing functions of these random variables are positively correlated, on every sublattice of the variables' domain. One consequence of affiliation, used repeatedly in the present analysis, is that $\frac{\partial}{\partial \theta} \frac{1-F(x \mid \theta)}{f(x \mid \theta)} \geq 0$.

${ }^{10}$ It is a restriction that $x$ be univariate. To our knowledge, there is no theory of bidding with multidimensional signals that does not readily reduce to the univariate signal case.

${ }^{11}$ Asymmetric equilibria, with some buyers participating with certainty and others not at all, exist. These equilibria lead to qualitatively similar results, and indeed avoid some of the problems associated with randomized participation. However, they also introduce an "integer problem," in that participation tends to be a step function of the reserve. See McAfee and McMillan (1987c) for an analysis of such equilibria in the independent private values framework.
} 
less than $r$ are ignored. Fourth, the bidder with the highest (final) submitted bid in excess of $r$ obtains the object, and pays a price that will depend on the specific auction form employed. If no buyer submits a bid exceeding $r$, the seller keeps the item and obtains the value $\sigma(\theta)$. The seller's value $\sigma$ is assumed nondecreasing in $\theta$. We consider in the theory the sale of a single object, and leave implicit in $\sigma$ the means by which the seller realizes the opportunity cost of sale. Bidders who don't purchase a signal obtain zero. Bidders who purchase a signal but fail to obtain the object obtain the von Neumann-Morgenstern utility $-s$, while bidders who pay $p$ for the object obtain $u\left(x_{i}, \theta\right)-p-s$.

A standard approach in analyzing equilibria in auctions with a fixed number of bidders is to conjecture that bids are monotonic functions of signals. This conjecture is then used to determine a probability of winning the auction for a given bid, $b$, and to determine the bidder's expected utility at the bid, $b$. The best response bid is calculated, symmetry imposed and the resulting bid function is then checked for the monotonicity assumption. In affiliated values auctions, monotonicity is generally implied by the supermodularity assumption embodied in affiliation. For a fixed participation ratio, $\rho$, we can conduct a similar analysis. Let $B(\bullet ; \rho)$ denote an equilibrium bidding function. ${ }^{12}$ A sufficient condition for $B(\bullet ; \rho)$ to be nondecreasing is the log supermodularity of $1-\rho(1-F(x \mid \theta)),{ }^{13}$ or

$$
\left(\forall x \geq x_{r}\right) \frac{\partial}{\partial \theta} \frac{f(x \mid \theta)}{1-\rho(1-F(x \mid \theta))} \geq 0
$$

Condition (1) is a sufficient condition for all the intuitive monotonicities derived below, and so we assume it here, although we note below when it is used. Affiliation of $f$ implies (1) for $\rho=1 .{ }^{14}$ The meaning

\footnotetext{
${ }^{12}$ In sealed bid auctions, $B(\bullet ; \rho)$ is a function of a bidder's signal alone. In ascending bid auctions, it is also a function of the bids at which rival bidders drop out. In this latter case, monotonicity means $B(\cdot ; \rho)$ is increasing in the signal $x$ for all values of drop out bids of rivals.

${ }^{13}$ See Athey (1995) for a discussion of log supermodularity and its application. The proof that this condition is sufficient for monotonicity is an adaptation of proofs in Milgrom and Weber (1982).

${ }^{14}$ Since Milgrom and Weber (1982) have $\rho=1,(1)$ holds in their model by affiliation. Inequality (1) must fail to hold globally if $\rho$ is very close to zero, and in particular fails for $x$ near its lower bound, as $\rho \rightarrow 0$. However, we need (1) only for $x \geq x_{r}$; this is feasible even for $\rho=0$. While a somewhat weaker condition will suffice for monotonicity of the bidding function (in particular, the log supermodularity of
} 
of assumption (1) is illustrated in the following thought experiment. Consider first the event of receiving exactly one bid, $B\left(x_{r} ; \rho\right)$, and second, observing no bids at all. Assumption (1) implies that the expected value of the good given the first event exceeds the expected value of the good given the second event (this is proved in Lemma 5 below). There are two circumstances under which a buyer does not bid: either the buyer received a signal less than $x_{r}$, or the buyer did not obtain a signal at all. That a buyer obtained no signal is "good news" (Milgrom (1981)) about the value of the object, relative to the knowledge that the buyer's signal was very low. Assumption (1) implies that it is better news to see a signal exactly equal to $x_{r}$, and hence a marginal bid, than to see no bid at all. Whether assumption (1) is plausible, then, depends on whether $x_{r}$ is sufficiently large that the signal $x_{r}$ is good news. The value of $x_{r}$ depends on $r$.

We denote expectation over $\theta$ by $E_{\theta}$. The ex ante density of a signal is then $h(x)=E_{\theta}[f(x \mid \theta)]$. We denote expected equilibrium profits of a bidder with signal, $x$, by $\pi(x)$. Note that in environments other than independent private values, this function will typically differ depending on the auction form that is used. Nevertheless, our results are robust to this indeterminacy. The screening level satisfies $\pi\left(x_{r}\right)=0$, or

$$
0=E_{\theta \mid}\left(u\left(x_{r}, \theta\right)-r\right)\left(1-\rho\left(1-F\left(x_{r} \mid \theta\right)\right)\right)^{n-1} f\left(x_{r} \mid \theta\right)_{]} .
$$

The participation decision, which determines $\rho$, is given by bidders' indifference between expending $s$ to become informed, and obtaining zero. This implies

$$
s=\int_{x_{r}}^{\infty} \pi(x) h(x) d x
$$

Equations (2) and (3) jointly determine $x_{r}$ and $\rho$.

One naturally expects that an increase in the reserve price $r$ would increase the screening level $x_{r}$ and decrease the participation probability $\rho$. That is,

$$
\frac{d x_{r}}{d r}>0, \text { and } \frac{d \rho}{d r}<0
$$

$(1-\rho(1-F))^{n-2} f^{2}$ would suffice), (1) is nevertheless the "natural" sufficient condition to combine with affiliation, especially as (1) is independent of $n$. 
However, this "natural" comparative statics does not hold in all environments. Indeed, it is possible to show that $\rho$ does not necessarily fall monotonically as $r$ rises. Consider a common value model as follows. Let $u(x, \theta)=\theta, \theta \in\{0,1\}, \operatorname{Prob}[\theta=0]=.5, \mathrm{~F}(x \mid \theta)=x^{\theta+1}$, and consider a single object sold at a second price auction. Figure 1 shows how $x_{r}$ and $\rho$ change with $r$ for the case with the maximum number of bidders equal to five. Although the non-monotonicity in $\rho$ is slight it appears robust and is more easily generated with higher values of $n$ than low values.

One reason for the non-monotonicity lies in the peculiar effect that increasing the number of bidders may have on expected bids and expected seller revenues in the presence of common values. Steven Matthews (1984) shows that expected buyer profits need not be monotonic in participation. Thus, if a rise in $r$, leads to an increase in $x_{r}$, holding $\rho$ fixed, for example, the initial impact may, as expected, be to lower bidder profits. In order to continue to satisfy the zero profit entry condition, it may be necessary either to raise or lower the expected number of bidders by raising or lowering $\rho$ depending on the effect of the number of bidders on bidder profits in the particular environment.

This observation suggests that as the common value feature vanishes, then the ambiguity of the impact of $r$ on $x_{r}$, and $\rho$ also disappears. With second price auctions, under private values, even with affiliation, this is indeed the case, as the following lemma shows. Lemma 1 does not require assumption (1).

Lemma 1: Suppose $u(x, \theta)=x$, Then (4) holds in second price auctions.

All proofs are contained within the appendix.

It is readily shown by differentiating (2) that at least one of the inequalities in (4) must hold. In addition, locally around $\rho=0,(4)$ holds, as we demonstrate below for second price auctions. This result depends on (1) holding. As $\rho \rightarrow 0$, inequality (1) requires that $x_{r}$ be sufficiently large. For example, suppose $\theta$ has support $\left[\theta_{L}, \theta_{H}\right]$. For $F(x \mid \theta)=x^{\theta+1}$, (1) holds if $x_{r} \geq \boldsymbol{e}^{-1 /\left(\theta_{H^{+}}\right)}$. Similarly, if $F(x \mid \theta)=1-\boldsymbol{e}^{-\lambda x / \theta}$, (1) is equivalent to $x_{r} \geq \theta_{H} / \lambda$.

Lemma 2: For s sufficiently large, so that $\rho$ is close to 0, (4) holds in second price auctions. 
There is a possibility of multiple solutions to (2) and (3), because expected buyer profits need not be monotonic in participation. We ignore this complication in the remainder of the analysis. Stability requires that, as participation increases, then expected profits fall, for otherwise a slight increase in bidders' beliefs about participation would lead to increased participation, reinforcing the expectation. Given stability, ${ }^{15}$ in the appendix, there is a simple to state, but difficult to interpret, sufficient condition imposed on the distribution $F$ for $x_{r}$ to rise and $\rho$ to fall with $r$.

\section{The Effect of Reserve Prices on Seller Profits.}

Since the ex ante surplus of buyers is zero, the seller obtains the gains from trade net of entry costs. ${ }^{16}$ Thus the seller wishes to select an efficient auction. Intuitively, this requires that the seller sell only when the expected value of the object to a bidder exceeds the seller's value, denoted $\sigma(\theta)$. However, we assume that the seller does not know the realization of $\theta$, and thus cannot trivially set an ex ante efficient reserve price. ${ }^{17}$ Denote the seller's surplus by $\Psi$. Assuming that the bids are monotonic in bidder signals and exploiting the fact that, in equilibrium, ex ante bidder profits are zero, a useful expression for $\Psi$ is (5) $\Psi=E_{\theta}\left[\sigma(\theta)+\int_{x_{r}}^{\infty}(u(x, \theta)-\sigma(\theta)) n(1-\rho(1-F(x \mid \theta)))^{n-1} \rho f(x \mid \theta) d x-n \rho s\right]$

Thus, the seller's payoff is the value of not selling, $\sigma(\theta)$, plus the net gains from trade when trade occurs, $u-\sigma$, evaluated at the highest signal received, minus the cost of buyer participation, $n \rho s$.

Expressed as in (5), the seller's value depends on the reserve $r$ only through the dependence of $x_{r}$ and $\rho$ on $r$. This fact explains why the analysis does not rely on the specific form of auction used. Note, however, the result does not imply that seller expected revenues are independent of the auction mechanism. The failure of revenue equivalence in affiliated auctions implies that different auction mechanisms will generate different

\footnotetext{
${ }^{15}$ Our formulation of stability depends not on (3) directly, but on (3) with $r$ replaced with the value solved out from (2).

16 A similar result is noted by McAfee and Vincent (1992) and Levin and Smith (1994).

${ }^{17}$ If the seller knows $\theta$, Milgrom and Weber (1982) show that the seller should announce $\theta$ to the bidders, in an environment where participation is exogenous.
} 
values for $x_{r}$ and $\rho$ for a given reserve price, $r$. For example, hold $x_{r}$ and $r$ fixed, and consider the equilibrium value of $\rho$ from a first price auction. Since we know that expected payments in second price auctions are weakly higher than in first price auctions, it must be the case that expected bidder profits would be lower at the same value of $\rho$. Since this value of $\rho$ yielded zero profits including entry costs in the first price auction, the same values of $x_{r}$ and $\rho$ can not represent an equilibrium in a second price auction.

Equation (5) makes clear that the effect of the reserve price instrument for a seller's expected revenues depends on how it changes $x_{r}$ and $\rho$. We have shown that these effects can be ambiguous. In this section, however, in this section we explore the consequences of changes in $r$, when $x_{r}$ and $\rho$ change with $r$ in the expected ways. Lemma 3 characterizes the effects of changes in $x_{r}$ and $\rho$ on the seller's payoff, which is used in establishing the effect of a change in the reserve, using (4).

Lemma 3: Assume (4) holds. ${ }^{18}$

$$
\begin{aligned}
& \frac{\partial \Psi}{\partial x_{r}}=-E_{\theta}\left[(r-\sigma(\theta)) n\left(1-\rho\left(1-F\left(x_{r} \mid \theta\right)\right)\right)^{n-1} \rho f\left(x_{r} \mid \theta\right)\right], \\
& \frac{\partial \Psi}{\partial \rho} \leq E_{\theta}\left[(r-\sigma(\theta)) n\left(1-\rho\left(1-F\left(x_{r} \mid \theta\right)\right)\right)^{n-1}\left(1-F\left(x_{r} \mid \theta\right)\right)\right] .
\end{aligned}
$$

Lemma 3 computes the value of increasing both the screening level $x_{r}$ and the participation probability $\rho$ to the seller, and in both cases relates these values to the difference between the reserve price and the seller's value. Increasing the screening value increases the seller's payoff if and only if the seller's value is less than the reserve price, evaluated at the circumstance where a buyer is just indifferent between paying the reserve and not purchasing (that is, the seller's expected value for the marginal property). In contrast, there are two effects from increasing the participation probability. The first effect, which is shown in (7), is that increasing $\rho$ increases the chance that exactly one buyer is willing to pay the reserve, a net gain to the seller of $r-\sigma$. In addition, there is a secondary effect which is nonpositive. In second price auctions, the effect is straightforward

\footnotetext{
${ }^{18}$ The provided proof of Lemma 3 is for second price auctions. A similar proof holds for first price and oral auctions and is available from the authors on request.
} 
to describe. There is a marginal loss which is the expected value of the second highest bidder, minus the expected payment of the highest bidder. For private values, this second term is zero, but in general the expected value of the second highest bidder (conditional on that bidder being second highest) exceeds the expected value of that bidder conditional on tying for being highest, which in turn equals the bid. ${ }^{19}$

We are now in a position to characterize a lower bound on the optimal reserve price, based on historical data for auctions of similar items. Theorem 4 depends on both (1) and (4). Define $\tilde{E}_{x}$ to be the expectation over $\theta$ conditional on the highest signal being $x$.

Theorem 4: Fix a reserve price $r_{0}$, and suppose that $r_{0}<\tilde{E}_{x_{r_{0}}}[\sigma(\theta)]=\sigma_{0}$, that is, the expected value of properties that just fail to sell is greater than the reserve. Then $\left.\frac{d \Psi}{d r}\right|_{r_{0} \leq r \leq 0_{0}} \geq 0$. Expected seller profits rise with a small increase in the reserve.

Theorem 4 indicates that if the expected value to a seller, $\sigma_{0}$, of properties that just fail to sell at a reserve price, $r_{0}$, is greater than $r_{0}$, then seller expected profits are rising in the reserve price for any reserve between $r_{0}$ and $\sigma_{0}$. In Figure 2, we graphically illustrate Theorem 4. The curve represents the expected value of marginal unsold items, $\tilde{E}[\sigma(\theta)]$. This depends on the reserve price through its effect on $x_{r}$ and $\rho$. If the reserve price is less than $\tilde{E}[\sigma(\theta)]$, increasing the reserve to $\tilde{E}[\sigma(\theta)]$ will still leave the reserve below the optimal one, denoted $r^{*}$. That $\tilde{E}[\sigma(\theta)]$ is increasing in $r$ is a consequence of affiliation, the monotonicity of $\sigma$, and (4). However, the uniqueness illustrated in Figure 2 cannot be guaranteed without placing further restrictions on $\sigma$.

Theorem 4 implies the following. Consider sales of houses, and suppose that the reserve price is less than the present value of resale for houses right at the margin, i.e. those with a bidder just indifferent between bidding and not. Then it is profitable for the seller to raise the reserve price to the present value of resale for

\footnotetext{
${ }^{19}$ Does a second price auction with ex post efficient reserve attract too many bidders? The answer is yes. Suppose the reserve price is chosen in such a way that (6) is zero, which is the ex post efficient reserve price. Then the right hand side of (7) is nonpositive. Consequently, if the reserve price is chosen in such a way that the seller's payoff is maximized with respect to the screening level, then the participation probability $\rho$ is too high. This observation, which appears empirically useless, does not depend on either assumptions (1) or (4).
} 
those houses. By itself, this implication of Theorem 4 would be difficult to implement empirically, because it is difficult to establish which houses were at the margin, that is, which houses had a bidder indifferent to bidding on them. ${ }^{20}$ However, the average value of unsold houses is less than the value of marginal unsold houses. While this proposition seems intuitive, it in fact relies upon inequality (1) for a proof. The reason the proposition might be less than obvious is that failing to attract any bidders at all may be a result of no bidders becoming informed, which could be good news about the value of the property, as compared with the event of attracting one marginal bidder. However, assumption (1) implies that attracting the marginal bidder is overall better news than the event of attracting no bidders at all, as the following lemma shows.

Lemma 5: $\frac{E_{\theta}\left[\sigma(\theta)\left(1-\rho\left(1-F\left(x_{r} \mid \theta\right)\right)\right)^{n-1} f\left(x_{r} \mid \theta\right)\right]}{E_{\theta}\left[\left(1-\rho\left(1-F\left(x_{r} \mid \theta\right)\right)\right)^{n-1} f\left(x_{r} \mid \theta\right)\right]} \geq \frac{E_{\theta}\left[\sigma(\theta)\left(1-\rho\left(1-F\left(x_{r} \mid \theta\right)\right)\right)^{n}\right]}{E_{\theta}\left[\left(1-\rho\left(1-F\left(x_{r} \mid \theta\right)\right)\right)^{n}\right]} \equiv \bar{\sigma}$.

Lemma 5 shows that the value of the good to the seller in the event that no bidders are attracted is less than the value of the good to the seller in the event that one marginal bid is attracted. Combining Theorem 4 and Lemma 5, we have:

Corollary 6: Suppose that the average value ō of unsold items exceeds the reserve price. Then raising the reserve price to ō increases seller revenue.

Corollary 6 depends only on observables, and contains a testable prediction. In particular, the average value to the seller of unsold items is often observable by the seller. In the data considered below, we observe houses that don't sell in an auction, and the later sale of these houses. From data on the later sale price, we construct a present value, and find that the present value to the seller of real estate that does not sell is about $75 \%$ of appraised value. This estimate is a lower bound of the appropriate reserve price.

\footnotetext{
${ }^{20}$ McAfee and Vincent (1992) propose a methodology for solving this problem, for common value auctions. The strategy requires the observation of ex post valuations, such as are available for the OCS oil auctions studied by Hendricks, Porter and Boudreau (1987). The technique is to look at the properties that received bids close to the reserve price, and estimate the distribution of ex post valuations conditional on a marginal winning bid. The entire database is used to estimate the expected winning bid conditional on the ex post value. Given this distribution of values for properties receiving marginal bids, it is then possible to estimate the average winning bid of marginal properties, which, with appropriate discounting, is approximately what could be expected if the properties were re-auctioned later.
} 
Corollary 6 and Theorem 4 both state quite intuitive economic propositions. Effectively, both results state that one shouldn't sell items for less than their value in an alternative use. These propositions hold in a broad set of circumstances. It is remarkable how difficult it is to establish what seem like obvious propositions. The source of the difficulty, of course, is the endogenous entry of bidders; alterations in the reserve price may have adverse impact on participation in auctions, and an intuition arising from models with exogenous participation doesn't account for this effect.

Typically, the seller who fails to sell in the current auction will generally attempt to sell again later; this is the case in the real estate auctions we study below. It is important to realize that our theory will accommodate this case. The theory itself accounts for the sample selection bias, in that the distribution of $\theta$ for items that fail to sell explicitly depends on the reserve price. Thus, we are considering the appropriate class of items that fail to sell. Furthermore, the theory suggests a way to enhance revenue, and therefore suggests a means of increasing the value of items that fail to sell, that is, increasing $\sigma$. As the theory will suggest that the average value of $\sigma$ conditional on no sale is a lower bound for the optimal reserve, the historical average value of $\sigma$ remains a lower bound on the optimal reserve after steps are taken to increase $\sigma$.

There are several limitations of the model that should be acknowledged, because these limitations are not entirely consistent with the application. We assume symmetry among the buyers. While this may be realistic for a given type of buyers, house auctions attract both buyers who desire a house to inhabit, and dealers or brokers, who will sell any properties they buy. These two types of buyers may have distinct value distributions, that is, both $u$ and $F$ may vary across the two classes. In addition, in our model, information collection is a discrete decision. In practice, information collection might be better modeled as a continuous variable. Moreover, we have assumed symmetry in the information collection, or participation, cost $s$. While we consider that constant participation cost is a better model in many applications than an exogenous set of bidders, a more general model than either case would posit a distribution of participation costs. We expect the 
analysis to be robust to such increasing costs, but the complexity of such a model is daunting. ${ }^{21}$ Finally, we remind the reader that condition (4) is a sufficient condition for the result. If either participation falls with an increase in the reserve price or the screening level falls with an increase in the reserve, then the impact of a rise in the reserve may (but not must) be reversed. We believe that (4) is the most likely result. In Section 4 we conduct a test that provides some empirical support for this presumption.

\section{FDIC Auctions}

As an example of how Corollary 6 can be implemented to determine if an insufficiently high reserve price was used, we collected auction information from 6 FDIC auctions held between November 1997 and November 1998. In these 6 auctions, a total of 137 properties with an appraised value of $\$ 34.8$ million were offered for sale. The auctions were moderately successful in that 90 or $65 \%$ of the properties were sold. For each auction we were able to obtain the total of the sale prices for all sold properties. Summary statistics from this data set are provided in Table 1.

\footnotetext{
${ }^{21}$ One reason to expect that Corollary 5 would continue to hold in a model with a distribution of participation costs is that the seller now has some monopoly power, and thus has an incentive to raise the reserve price above the socially optimal level. Thus, our analysis of the socially optimal reserve should remain a lower bound. The analysis, however, is even more complicated than the current study, for there must now be a critical level of the participation cost, so that agents with lower participation cost choose to participate.
} 
Table 1: FDIC Summary Statistics

\begin{tabular}{|l|rrrrrrr|}
\hline Auctions & DC-1 & DC-2 & FL-2 & Louisiana & Arkansas & AL,GA,\&MS & Total/Average \\
\hline Number of Properties Auctioned & 39 & 14 & 41 & 19 & 9 & 15 & $\mathbf{1 3 7}$ \\
Total Appraised Value & $\$ 24,514,180.00$ & $\$ 2,440,001.00$ & $\$ 5,875,800.00$ & $\$ 1,052,200.00$ & $\$ 236,930.00$ & $\$ 700,250.00$ & $\mathbf{\$ 3 4 , 8 1 9 , 3 6 1 . 0 0}$ \\
Number Sold at Auction & 29 & 11 & 33 & 6 & 2 & 9 \\
Total Revenue Raised at Auction & $\$ 7,020,068.00$ & $\$ 986,700.00$ & $\$ 4,123,910.00$ & $\$ 242,545.00$ & $\$ 31,200.00$ & $\$ 172,802.00$ & $\mathbf{\$ 1 2 , 5 7 7 , 2 2 5 . 0 0}$ \\
Avg. Sale Price & $\$ 242,071.31$ & $\$ 89,700.00$ & $\$ 124,966.97$ & $\$ 40,424.17$ & $\$ 15,600.00$ & $\$ 19,200.22$ & $\mathbf{\$ 1 3 9 , 7 4 6 . 9 4}$ \\
Appraised Value Unsold Properties & $\$ 14,981,000.00$ & $\$ 151,000.00$ & $\$ 152,500.00$ & $\$ 766,900.00$ & $\$ 205,630.00$ & $\$ 379,850.00$ & $\mathbf{\$ 1 6 , 6 3 6 , 8 8 0 . 0 0}$ \\
Number Of Properties Later Sold & 11 & 3 & 8 & 13 & 7 & 6 \\
Total Sales Revenue -- Later Sales & $\$ 11,214,500.00$ & $\$ 51,500.00$ & $\$ 30,265.00$ & $\$ 95,087.50$ & $\$ 111,600.00$ & $\$ 312,400.00$ & $\mathbf{\$ 1 1 , 8 1 5 , 3 5 2 . 5 0}$ \\
Avg. Sales Price -- Later Sales & $\$ 1,121,450.00$ & $\$ 17,166.67$ & $\$ 4,323.57$ & $\$ 8,644.32$ & $\$ 15,942.86$ & $\$ 71,480.00$ & $\mathbf{\$ 1 , 2 3 9 , 0 0 7 . 4 1}$ \\
S.D. of Sales Price -- Later Sales & $\$ 1,944,450.86$ & $\$ 19,775.83$ & $\$ 4,727.50$ & $\$ 21,461.70$ & $\$ 23,376.64$ & $\$ 120,602.87$ & $\mathbf{\$ 2 , 1 3 4 , 3 9 5 . 3 9}$ \\
Avg. Days Before Later Sales & 336 & 266 & & 270 & 202 & 112 & 161 \\
Avg. PVSP -- Later Sales & $\$ 1,080,885.70$ & $\$ 16,547.67$ & $\$ 4,146.69$ & $\$ 8,369.72$ & $\$ 15,643.82$ & $\$ 69,302.99$ & $\mathbf{\$ 1 9 9 , 1 4 9 . 4 3}$ \\
\hline
\end{tabular}


Three of the auctions were oral and the remaining three were sealed-bid auctions. In the oral auctions, bidders are deemed eligible upon providing evidence of $\$ 2000$ of verifiable funds for each property the bidder intends to purchase. A successful bidder must close the transaction within 30 days or forfeit a deposit equal to $5 \%$ of the purchase price. Similar deposits and rules of forfeiture are enforced for the sealed-bid auctions. The FDIC does not reveal reserve prices. In their promotional brochure, the FDIC stipulates that some properties may be sold "absolute" or with no reserve prices provided there is a minimum of two non-related, qualified bidders. However, discussions with FDIC officials indicate that they often withdraw the property from the auction if bids do not reach their implicit reserve price expressed as a percentage of the property's appraised value.

The unsold properties were located throughout the country (14 were from the Washington DC area, 8 from Florida, 13 from Louisiana, and 13 were from 4 southeastern states) and numerous property types were represented. Of the properties offered at auction, 48 properties (valued at $\$ 16.7$ million at the time of the auction) were not sold at auction. Of these, 43 were either eventually sold (38) or are currently pending or awaiting FDIC's acceptance of an outstanding offer. At present, 4 are still unsold and 1 was withdrawn from sale. For the 43 sold or pending properties, the average time between the auction date and their eventual sale was 229 days or approximately 8 months. For the 38 properties which were subsequently sold, the sales price was on average $50 \%$ of the appraised value

The reserve prices were not announced. ${ }^{22}$ The secret reserve prices must create some uncertainty in the minds of the bidders, however, we proceed under the assumption that the bidders had a reasonably good estimate of the reserve. Given that published accounts of FDIC rules provided some information about the

\footnotetext{
${ }^{22}$ According to the FDIC's Asset Disposition Manual, "Disclosure of estimated cash recovery or reserve or minimum prices on loans or packages of loans or ORE properties can cause competitive harm to the Corporation. They should not be disclosed except to anyone legally entitled to such information. Case by case disclosure of minimum bid prices prior to a sale is allowed, however, as part of an integrated marketing strategy."

The frequent use of secret reserve prices by sellers (Ashenfelter (1989)) is mysterious, given that auction theory tends to support announcing the reserve. Vincent (1995) provides a theoretical rationale for secret reserve prices. An open policy of announced reserves would appear to have two advantages. First, sellers should find it easier to commit to a reserve other than the ex post efficient reserve, since with an announced reserve, it can more readily be verified that sellers followed their announced policy. Second, a secret reserve would tend to unravel, in that sellers with unusually high opportunity cost of sale would tend to announce their reserve to force bids up.
} 
reserve price, this assumption does not seem unreasonable. In addition, it is not uncommon for sellers in oral auctions to indicate when the bidding has failed to meet the reserve (e.g. by takings bids "from the chandelier"), thus giving bidders a chance to increase the bid and meet the reserve; such a policy, if understood by bidders, has the effect of revealing the reserve price. In the next section, we consider a smaller data set with published reserve prices. For an analysis of secret reserve prices, see Hendricks, Porter and Wilson (1994).

We are reasonably certain that the reserve price was at least $10 \%$ less than the appraised value, and typically $50 \%$ less. $^{23}$ For the 6 auctions the sale price was on average $75 \%$ of appraised value. In one auction in which 11 of 14 properties were sold, the sale prices were $43 \%$ of appraised value. Since properties are never sold for less than the reserve, this ratio provides an upper bound on the average value of the reserve, at least among the properties that sold initially. ${ }^{24}$ Bidding less than the reserve price is not necessarily an absolute barrier to sale; the FDIC would negotiate with buyers who failed to meet the reserve, but were close. As additional evidence, we observed four auctions by the First Interstate Bank in Austin, Texas, with an announced reserve. In these instances, the reserve averaged $48 \%$ of appraised value. The data from these auctions are utilized in the next section.

Each auction contained multiple properties. For these sales, we obtained appraised value $(A V)$, which averaged $\$ 347,018$, and eventual transaction date and price, directly from the FDIC. Only one observation, a property with a zero appraised value and which was later withdrawn, was omitted. The appraised value in the data was the prevailing appraised value at the time of the first auction. ${ }^{25}$ To construct the present value of future sale price (PVSP), we discounted the future resale price using a 5\% interest rate, which exceeds the

\footnotetext{
${ }^{23}$ According to an Associated Press review of congressional reports, agency documents and land records, "RTC routinely sells property at $50 \%$ of the appraised value, or less." (Austin American Statesman, July 11, 1994, p. A11).

There is a potential sample selection bias in this data, since reserve prices are not observed. If some of the reserves exceeded the optimum, then relatively valuable properties would be counted in the seller's value of not selling, biasing our estimate of the seller's value.

${ }^{24}$ Of course, we cannot rule out the possibility that the properties which failed to sell had an unusually high reserve price.

${ }^{25}$ We obtained the appraised value directly from the FDIC.
} 
short term government bond or money market rates, but is less than the mortgage rate for the period. The variable PVSP plays the role of $\sigma(\theta)$ (conditional on no sale) in the theoretical analysis, for it represents the current value to the government of failing to sell. The average value of PVSP was $\$ 209,953$. In the case of properties that remained unsold, we assigned a value of zero.

Adapting the theory, and in particular Corollary 6, to this environment is straightforward. ${ }^{26}$ The first step is to construct an estimate of the mean value of unsold properties conditional on any publicly available information. The only observable that is linked to value is the appraised value, and this was publicly known. (We assume that the appraised value is a sufficient statistic for all the information available to the seller at the time of the auction.) Moreover, since the appraised value is an attempt to estimate the actual value of the property, one expects that both the discounted future sale price $(P V S P)$ and the appropriate reserve should be a percentage of the appraised value. With this in mind, we regress $P V S P$ on appraised value $(A V)$ to determine the seller's best estimate of the opportunity cost of selling given the information available. It is not obvious whether this regression should include or exclude a constant term. Of course, including a constant yields a better estimate of the relationship between $P V S P$ and $A V$. However, typical reserve price policies appear to be based on a direct linear relationship with $A V$ suggesting that sellers may ignore this possibility for developing an improved estimate.

Using Corollary 6, a lower bound on the appropriate reserve is the average PVSP conditional on no sale. The next step is simply to compare the relationship between this average and $A V$ to (a candidate) relationship between reserve price and $A V$. It is important to realize that the sample selection bias - that the properties that didn't sell at auction are not representative of the properties auctioned - is accounted for by the

\footnotetext{
${ }^{26}$ Corollary 6 assumes that the seller is maximizing revenue, or, alternately, maximizing social efficiency (since the two notions coincide in the model). While the government considered other criteria as well as revenue, the Asset Disposition Manual of the FDIC lists as its first criterion "Timely sales which maximize recovery to FDIC on a net present value basis." None of the other criteria are inconsistent with revenue maximization, and include the use of seller financing, education of the brokerage community, fair treatment of the pubic, provision of accurate information, and compliance with the law.
} 
theory. In setting a reserve price, the seller knows that low quality properties will fail to meet the reserve, and a lower bound for the appropriate reserve price is the value of these low quality properties.

We regressed $P V S P$ on the appraised value, both with and without a constant. In the regression with a constant, the constant is not significant $(t=-0.80)$, and the coefficient on appraised value is 0.745 , with a $t$-statistic of 13.9. The lower bound on a $95 \%$ confidence interval is 0.637 . Without a constant, the coefficient on appraised value is 0.730 , with a $t$-statistic of 14.4 . In this case, the lower bound on the $95 \%$ confidence interval is 0.629 . The adjusted $R^{2}$ is 0.815 , indicating that the fit is quite good. With $10 \%$ discounting, the coefficient on appraised value drops to .689 , with a $t$-statistic of 14.4 .

In case there were unobserved auction specific effects that entered into the relationship between $P V S P$ and $A V$, we attempted to account for them by a fixed effects regression, allowing for some auction specific variation. In this case, the constant remains insignificant but the coefficient on $A V$ rises to 0.78 with a $t$-statistic of 11.9 and a lower bound on the confidence interval of 0.65 . This specification added little to the estimation, however. An F-test that all six auction specific constants were identical easily accepted the null $(F(5,40)=0.27)$ as did test of the hypothesis that all six constants were zero. ${ }^{27}$

Another issue is heteroscedasticity. If there are object or auction specific features that are responsible for difference in variances, then the estimated standard errors will not be correct. Using White's test for heteroscedasticity, both the OLS and the fixed effects regressions yielded rejections of the hypothesis of no heteroscedasticity. The OLS regression using White's heteroscedastic-robust standard errors yielded a lower bound on the confidence interval for the appraised value coefficient of 0.41 , probably below any reserve price in effect. If the variance of the regression of $P V S P$ on $A V$ was linear in the appraised value, then a weighted least squares regression would be appropriate using $A V$ as the weight. This approach yielded a coefficient

\footnotetext{
${ }^{27}$ A random effects specification yielded the same results as the full sample OLS because the estimated variance of the random effects component was zero.
} 
estimate of 0.61 and a $95 \%$ lower confidence interval bound of $0.49 .{ }^{28}$ If, on the other hand, the standard deviation of the regression was linear in appraised value, the resulting weighted regression yields the much lower coefficient estimate of .37 and a $95 \%$ lower confidence interval bound of 0.26 .

An interesting question arises concerning our assumption that bidders must incur the signal cost $s$ is necessary in order to participate in the auction..$^{29}$ Without this assumption, the standard monotonicity results in auction theory no longer applies since uninformed bidders will generally be more optimistic than informed bidders with pessimistic signals. Nevertheless, we can investigate the incentives for bidders to follow a strategy of simply always bidding the reserve in the hopes of acquiring otherwise unsold properties and later reselling them. Suppose a bidder used such a strategy (for all properties) and later was able to sell the property for the same price as the government received. Table 2, Column 2 shows what the strategy would yield in discounted expected profits, gross of bidding costs, under different assumptions about what the reserve price policy actually was. The final column shows what the maximum value of $s$ would have to be in order to make such a strategy unprofitable assuming $s$ is expended for each property bid on. Thus, if the reserve price was $60 \%$ of the appraised value and if the winning bidder expected to obtain the same later price as the FDIC for properties that did not otherwise sell at the auction, a bidder who ignored all information and just bid the reserve would make money if it cost less than $\$ 600$ to submit a bid. The strategy would yield zero expected profits (gross of the bidding cost) at a reserve price policy of just under $61 \%$. The table suggests that if a very low reserve price was used, it would have created quite a strong incentive to arbitrage against the government. However, the conclusion requires the assumption that any such bidder could mimic or improve on the government's resale practice.

\footnotetext{
${ }^{28}$ Yet a further issue is the assumed independence of the observations per property. We see no obvious way to address this potential problem and leave it as an open question.

${ }^{29}$ We are grateful to both referees for suggesting this exercise.
} 
Table 2: Rewards to Uninformed Bidding.

\begin{tabular}{|l|l|l|}
\hline Reserve Price Policy & Discounted Expected Profits & Maximal Entry Cost \\
\hline .5 & $\$ 1,749,307$ & $\$ 12676$ \\
\hline .6 & $\$ 83,618$ & $\$ 605$ \\
\hline .75 & $-\$ 2,414,913$ & $-\$ 17,499.4$ \\
\hline
\end{tabular}

\section{Testing the Theory}

The analysis of the previous section is subject to several criticisms, the most serious is the validity of the maintained assumptions of the model. In addition, for most of the sample, reserve prices were kept secret, which has an unknown effect on the theory itself. To assess the empirical validity of the conclusion that reserve prices of $50 \%$ of appraised value are too low, we collected an additional data set of first time sales from for auctions with published reserve prices, and assessed whether the properties with relatively high reserves brought higher prices on average.

The data come from four oral auctions held by First Interstate Bank between April 1990 and September 1991 for properties throughout Texas. Although each auction was for multiple properties throughout Texas (1036 properties), our sample is from sales in Travis, Harris and Dallas counties since we obtained access to their central appraisal office records. In all four auctions, registered bidders are required to provide a $\$ 3000$ deposit for each property they plan to bid on. All sales below a predetermined threshold (two auctions at $\$ 15,000$ and two at $\$ 25,000$ ) had to be purchased with all cash within 10 days. For sales exceeding such thresholds, the seller is required to provide a 5\% deposit and has 30 days to close. The bidder's inability to provide with the remaining cash or financing within the time period resulted in the forfeit of his deposit. Many of these properties were poorly described in the auction brochure; there is no reason to think that a poor description in the auction listing is correlated with any other variable, but we can not rule out such a 
correlation (and consequent sample selection bias). We were able to obtain appraised values for 52 properties, including 7 commercial buildings, 19 residential properties, and the remainder residential and commercial lots.

Of the 52 properties for which we have complete data, 45 sold in the auction and 7 sold later. The reserve price averaged $39 \%$ of appraised value for the properties that sold, and $52 \%$ for the properties that didn't sell, suggesting that high reserve prices significantly increased the likelihood that the property failed to sell. The present discounted average sale price of properties that initially failed to sell was .76 of their appraised value (standard deviation .36), in line with the data examined in the previous section. For buildings that didn't sell, PVSP was .93 of appraised value..$^{30}$

We computed the variable PVSP for these data. With properties that failed to sell, $P V S P$ is computed as before. For properties that sold in the auction, PVSP is the undiscounted sale price. As a first attempt to assess the effect of reserve prices on final sale prices, we regressed PVSP/AV, the percent of the appraised value obtained by the seller, on $r / A V$, the reserve price as a percent of appraised value, with a constant. The results are reported in Table 3, with $t$-statistics in parentheses. The reserve appears to be significant in increasing the sale price. The data are plotted in Figure 3 with PVSP plotted against the reserve price, both as a percentage of appraised value.

\begin{tabular}{lclll}
\multicolumn{5}{c}{ Table 3: Relationship of $\boldsymbol{P} \boldsymbol{V S P}$ and $\boldsymbol{A} \boldsymbol{V}$ by Type of Property ${ }^{31}$} \\
Type & Number & $\boldsymbol{r} / \boldsymbol{A} \boldsymbol{V}$ Coefficient & Constant & Adj. $\boldsymbol{R}^{\mathbf{2}}$ \\
All Buildings & 26 & $0.79(4.3)$ & $0.41(4.2)$ & .414 \\
All Land & 26 & $1.10(4.9)$ & $0.23(2.9)$ & .484 \\
All & 52 & $1.01(7.9)$ & $0.28(4.8)$ & .555
\end{tabular}

A more flexible approach is to regress $P V S P$ on the reserve price and the appraised value. The logic underlying this approach can be interpreted in the following way. Suppose that the statistical model generating the reserve price and $P V S P$ was given by

\footnotetext{
${ }^{30}$ For the properties sold by the First Interstate, we obtained the assessed value prevailing prior to the auction from county records; these are generally updated every two years.

${ }^{31} t$-statistics in parentheses.
} 


$$
\begin{gathered}
r=\delta+\mu * A V+\kappa * v+\epsilon_{r} \\
P V S P=\alpha+\beta * A V+\gamma * r+\nu+\epsilon_{p}
\end{gathered}
$$

where the error terms, $\epsilon_{\mathrm{r}}$ and $\epsilon_{p}$ are independent. This model assumes that there are two separate stochastic processes, one determining the reserve price and another determining seller revenues. Both the realized reserve price and the present value of seller revenues are partially determined by the appraised value. In addition, there may be an auction specific term, v, which is unobserved by the econometrician. Furthermore, in a general specification, the realized reserve price may also affect seller revenues. If $\kappa=0$, (or if $\sigma_{v}=0$ ) we can simply run the second regression directly to test the null hypothesis that $\gamma$ is non-positive because, in this case, the regressors are independent of the error term $\epsilon_{p}+v$. For a regression on all properties, this approach yields a significantly positive estimate of 0.98 on the reserve price coefficient with a t-statistic of 7.3 and a coefficient on $A V$ of 0.21 ( $t=3.6$ ), with an $R^{2}$ of 0.91 while the constant is marginally significant. The t-statistics were computed using White's heteroscedastic-corrected standard errors. These results suggest that a rise in the reserve will have a positive effect on seller revenues.

Unfortunately, we cannot rule out on the basis of the evidence that higher reserves are correlated with higher sale prices because of errors in appraisals observable to the participants but not recorded. In the model above, the auction specific term, $v$, that may be observable to the seller and buyers, but not to us as researchers would lead the seller both to raise the estimate of PVSP and increase the reserve price. In this case, then, the reserve price will be higher precisely when the appraised value is erroneously low. Our data set does not include any potential instruments that would allow us to test for this effect. However, note that observable errors in appraisals would not tend to increase the likelihood that such properties fail to sell. In fact, the properties that failed to sell had higher reserves as a percentage of appraised value than the properties that sold suggesting that observable errors in appraisals can not be the entire reason for significance of reserve prices in predicting sale prices. 
If the seller had better information than the buyers about errors in appraisals, perhaps because the seller is observing day-to-day transactions prices and hence updating more frequently, then the seller would post higher reserves precisely when the property is more valuable than the appraisal indicates. In this circumstance, properties with higher reserves would sell for more, relative to appraisals, and higher reserves would be correlated with a greater chance of not selling, because buyers are poorly informed. In such a circumstance, the seller has an incentive to commit to the policy of informing the buyers, although such a commitment may be difficult to sustain. However, information on recent transactions is available to buyers, which should mitigate, if not eliminate, the effects of private information held by sellers. However, it is possible that private information held by sellers accounts for the positive effect of reserve prices on seller revenues (see Quan and Quigley, 1991, for a more extensive discussion and theoretical analysis of errors in appraisals).

\section{Conclusion}

In a bidding model with endogenous entry, this paper demonstrates the quite intuitive conclusion that the seller should post a reserve price at least as large, and generally strictly larger, than the average value (to the seller) of goods that fail to meet the reserve. The intuition for this conclusion rests on two observations. First, if entry into the auction is endogenous, ex ante bidder profits are zero, and thus the seller captures all the gains from trade. For this reason, the seller wishes to post a reserve that maximizes the expected gains from trade. Second, this reserve is at least the seller's alternate use value. This second observation is deceptive, for a change in the reserve price will generally alter the bidders' participation decisions, which affects the sellers' surplus. Indeed, the seller generally wishes to post a reserve strictly higher than the seller's value of items retained at the margin, because this reduces the duplication of investment in information by bidders. Under private values, the seller wishes to post a reserve between the seller's value for marginal items (where the highest bidder is just indifferent between paying the reserve and not) and the average value to the seller of items that sell at the reserve price. 
In addition, we demonstrated that the lower bound is at least as large as the average value of items that fail to sell. This result seems intuitive, in that the value of items that just fail to sell at the posted reserve would presumably exceed the value of items that didn't come close to selling. However, this intuition is complicated by the fact that there are two reasons an item might fail to sell. First, a bidder considered bidding and decided the reserve was too high. The value of these items is less than the value of items at the margin of not selling. Second, an item will not sell if no bidder considered purchasing it. These items have a value distributed like the ex ante value, which is potentially larger than the value of items at the margin of not selling. However, under the sufficient condition for the equilibrium bidding function to be monotonic, the first reason dominates the second, and on average, items that fail to sell are worth less than those right at the margin of not selling.

We, thus, have a testable prediction: if the reserve price is less than the average value to the seller of items that fail to meet the reserve in previous auctions, raising the reserve price to the average value of unsold items will increase seller revenue on average. This prediction is also a prescription for raising seller revenue.

We tested the theory using data on auctions with published reserve prices. The test is not as powerful as one might desire, because of limited sample size, some possibility of selection bias in data acquisition, and because of alternative explanations for expected sale prices increasing in the reserve. Nevertheless, we do find that increasing the reserve price significantly increases the expected present value of sale, in spite of the greater risk of not selling associated with higher reserves, which is consistent with the theory.

The result is applicable in a variety of contexts, including oil leases and other mineral rights, real estate, radio spectrum, timber, used cars, and other items where a sequence of similar or related items are to be sold. We applied the lower bound to real estate auctions. We find that the reserve price for buildings should be at least $75 \%$ of the appraised value. Considerations of management costs could lower this bound. to the 65$70 \%$ level, which was commonly used by the RTC and FDIC, but still exceeds the 50-60\% percent levels used in some circumstances. Further empirical work, using data from auctions in other regions and other time periods, is clearly advised before definitive conclusions are drawn. 
A natural question to ask is: should you sell your own home with an auction, using a reserve of $75 \%$ of the appraised value? It might seem that one can't go far wrong using such an auction, provided appraised value is sufficiently close to the expected market value. Indeed, by saving the real estate agency fees, this procedure may be at worst as good as the most common selling procedure. ${ }^{32}$ Caution is advised, however, since our data include only homes held by institutions, and these may be qualitatively different than privately held homes. In particular, some of the RTC and FDIC homes were in poor condition, and auctioning of homes appears to create a stigma of distressed real estate, attracting a distinct class of buyers that may not include the individuals willing to pay the most for homes in good condition. ${ }^{33}$ Auctioning of a home may signal poor quality even when the home is in good condition, and thus auctioning may not be a desirable transaction mechanism for well-maintained homes. ${ }^{34}$

We consider that the auction model with endogenous entry is a significant improvement in realism over models with exogenous participation. Endogenous entry implies that the seller maximizes revenue by maximizing ex ante social surplus, which simplifies parts of the analysis. However, endogenous entry also complicates the analysis, and plausible economic propositions, such as an increase in the reserve price decreasing bidder participation, appear difficult to prove in general. It seems evident that log supermodularity, so useful in environments with exogenous participation, is inadequate for environments with endogenous participation, and further work on the theory of auctions with endogenous participation is warranted. Finally, while endogenous entry represents an increase in realism, our model is hardly an exact representation of real auctions, as described by Ashenfelter (1989).

\footnotetext{
32 Ashenfelter and Genesove (1992) find that condominia sell for significantly more when auctioned than under bargaining.

${ }^{33}$ As auctions are not familiar to most home buyers, it may be that the desired buyers possess a higher cost of becoming informed than do the buyers of distressed real estate, which is more commonly sold by auction, merely because of the unfamiliarity of auction sales. For more information, see Quan (1994).

${ }^{34}$ One reason for auctioned homes to be poorly maintained is that often they came to be held by institutions because the owners were unable to pay the mortgage, a situation that doesn't encourage investment in maintenance. It is a curious fact that no such stigma is attached to auctioning of houses in New South Wales, Australia, where auctions with reserve price are the most common transaction method.
} 
The model contains two endogenous variables, the probability of participation $\rho$ and the screening value $x_{r}$, but we considered alterations of only one exogenous variable, the reserve price $r$. It is thus likely that using a second control variable, such as an entry fee, will permit better seller optimization. As a practical matter, most auctioneers do not charge entry fees, although there are notable exceptions. If optimal entry fees turn out to be negative, charging the negative entry fee is subject to a severe moral hazard problem, with people participating only in order to collect the negative entry fee. Moreover, establishing the effects of entry fees would require quantitative, rather than qualitative, information on the signs of the comparative statics in (4). Nevertheless, an attempt to establish bounds on optimal entry fees appears to be an important unsolved problem. 


\section{References}

Ashenfelter, Orley, "How Auctions Work for Wine and Art," Journal of Economic Perspectives 3, 1989, 2336.

Ashenfelter, Orley and David Genesove, "Testing for Price Anomalies in Real-Estate Auctions", American Economic Review (Papers and Proceedings) 82, May, 1992, 501-05.

Athey, Susan, "Monotone Comparative Statics in Stochastic Optimization Problems," Stanford University mimeo, 1995.

Harstad, Ronald, "Alternative Common-Value Auction Procedures: Revenue Comparisons with Free Entry" Journal of Political Economy 98, 1990, 421-429.

Hendricks, Kenneth, Robert Porter, and Bryan Boudreau, "Information and Returns in OCS Auctions: 19541969", Journal of Industrial Economics 35, June 1987, 517-42.

Hendricks, Kenneth, Robert Porter, and Charles Wilson, "Auctions for Oil and Gas Leases with an Informed Bidder and a Random Reservation Price", Econometrica 62, November, 1994, 1415-1144.

Hendricks, Kenneth and Robert Porter, "Joint Bidding in Federal OCS Auctions", American Economic Review (Papers and Proceedings) 82, May, 1992, 506-511.

Levin, Dan and James L. Smith, "Equilibrium in Auctions with Entry", American Economic Review 84, No. 3, June, 1994, 585-599.

Matthews, Steven, "Information Acquisition in Discriminatory Auctions," in M. Boyer and R. E. Kihlstrom, eds., Bayesian Models in Economic Theory, Elsevier Science Publishers, 1984.

McAfee, R. Preston, and John McMillan, "Auctions and Bidding", Journal of Economic Literature 25, 1987a, 699-738.

McAfee, R. Preston, and John McMillan, "Auctions with a Stochastic Number of Bidders", Journal of Economic Theory 43, 1987b, 1-19.

McAfee, R. Preston, and McMillan, John, "Auctions with Entry," Economics Letters 23, 1987c, 343-7.

McAfee, R. Preston, John McMillan and Philip Reny, "Extracting the Surplus in Common Value Auctions," Econometrica 57, no. 6, November, 1989, 1451-9.

McAfee, R. Preston and Philip Reny, "Correlated Information and Mechanism Design," Econometrica 60, No.2, March 1992, 395-421.

McAfee, R. Preston, and Vincent, Daniel, "Updating the Reserve Price in Common Value Auctions," American Economic Review (Papers and Proceedings) 82, May, 1992, 512-8.

McAfee, R. Preston, and Vincent, Daniel, "Sequentially Optimal Auctions," CMSEMS Discussion Paper No.1104, Northwestern University, 1994. 
Milgrom, Paul, "Good News and Bad News: Representation Theorems in Economics," Bell Journal of Economics 2, Autumn, 1981, 380-91.

Milgrom, Paul, "The Economics of Competitive Bidding: A Selective Survey", in Leonid Hurwicz, David Schmeidler and Hugo Sonnenschein, eds., Social Goals and Social Organization, Cambridge: Cambridge University Press, 1985.

Milgrom, Paul, and John Roberts, "Rationalizability, Learning and Equilibrium in Games with Strategic Complementarities", Econometrica 58, November, 1990, 1255-1278.

Milgrom, Paul and Robert Weber, "A General Theory of Auctions and Bidding", Econometrica 50, November 1982, 1089-1122.

Quan, Daniel C., "Real Estate Auctions: A Survey of Theory and Practice," Journal of Real Estate, Finance and Economics 9, 1994, 23-49.

Quan, Daniel C. and J. Quigley, "Price Formation and the Appraisal Function in Real Estate Markets," Journal of Real Estate, Finance and Economics 4, no. 2, June, 1991, 127-146.

Vincent, Daniel, "Bidding off the Wall: Why Reserve Prices May be Kept Secret," Journal of Economic Theory 62, April 1995, 575-584.

Wilson, Robert, "Strategic Analysis of Auctions", in Robert Aumann and Sergio Hart, eds., The Handbook of Game Theory, Amsterdam: North-Holland, 1991. 


\section{Appendix}

Proof of Lemma 1: Substituting $u(x, \theta)=x$ into (2), we have $x_{r}=r$. From (4), $B(x)=x$. Thus, by (3):

$$
\begin{aligned}
s= & E_{\theta[} \int_{x_{r}}^{\infty} f(x \mid \theta)\left[(x-r)\left(1-\rho\left(1-F\left(x_{r} \mid \theta\right)\right)\right)^{n-1}\right. \\
& +\int_{x_{r}}^{x}(x-y)(n-1)(1-\rho(1-F(y \mid \theta)))^{n-1} \rho f(y \mid \theta) d y_{]} d x_{]} \\
= & E_{\theta[} \int_{r}^{\infty} f(x \mid \theta)_{[}(x-r)(1-\rho(1-F(r \mid \theta)))^{n-1}+\left.(x-y)(1-\rho(1-F(y \mid \theta)))^{n-1}\right|_{r} ^{x} \\
& +\int_{r}^{x}(1-\rho(1-F(y \mid \theta)))^{n-1} d y_{]} d x_{]} \\
= & \left.E_{\theta[} \int_{r}^{\infty}(1-F(x \mid \theta))(1-\rho(1-F(x \mid \theta)))^{n-1} d x\right] .
\end{aligned}
$$

The right hand side is obviously decreasing in both $r$ and $\rho$, which gives a unique solution with $x_{r}=r$ increasing in $r$, and $\rho$ decreasing in $r$.

Proof of Lemma 2: Note that (1) implies $f\left(x_{r} \mid \theta\right)$ is nondecreasing in $\theta$. Because of the complexity of some of the terms below, we adopt the convention that $u, F$ and $f$ are evaluated at $\left(x_{r}, \theta\right)$ and $\left(x_{r} \mid \theta\right)$ unless otherwise indicated. We also denote $E_{\theta}$ by $E$. Recall that

$$
\tilde{E}(\bullet)=\frac{E(\bullet)(1-\rho(1-F))^{n-1} f}{E(1-\rho(1-F))^{n-1} f}
$$

We will use the following lemma several times.

Lemma A: $\frac{E(1-F)^{2}}{(E(1-F))^{2}} \geq \frac{E(1-F) f}{E(1-F) E f} \geq \frac{E f^{2}}{(E f)^{2}}$.

Proof of Lemma A:

$$
\begin{aligned}
& E(1-F)^{2}=E \frac{1-F}{f}(1-F) f=E f \frac{E \frac{1-F}{f}(1-F) f}{E f} \geq E f \frac{E \frac{1-F}{f} f}{E f} \frac{E(1-F) f}{E f}=\frac{E(1-F)}{E f} E(1-F) f . \\
& E(1-F) f=E \frac{1-F}{f} f f=E f \frac{E \frac{1-F}{f} f f}{E f} \geq E f \frac{E \frac{1-F}{f} f}{E f} \frac{E f^{2}}{E f}=\frac{E(1-F)}{E f} E f^{2} .
\end{aligned}
$$

By (2), $r=\tilde{E} u$.

$$
\left.\frac{\partial \tilde{E} u}{\partial x_{r}}=\tilde{E} u_{x}+\rho(n-1) \tilde{E} u \frac{f}{1-\rho(1-F)}-\tilde{E} u \tilde{E} \frac{f}{1-\rho(1-F)}\right]+\tilde{E} u \frac{f_{x}}{f}-\tilde{E} u \tilde{E} \frac{f_{x}}{f}>0 .
$$




$$
\left.\frac{\partial \tilde{E} u}{\partial \rho}\right|_{\rho=0}=-(n-1)[\tilde{E} u(1-F)-\tilde{E} u \tilde{E} 1-F]<0 .
$$

Thus, $1=\frac{\partial \tilde{E} u}{\partial x_{r}} \frac{d x_{r}}{d r}+\frac{\partial \tilde{E} u}{\partial \rho} \frac{d \rho}{d r}$, and either $\frac{d x_{r}}{d r}>0$ or $\frac{d \rho}{d r}<0$.

Eliminate $r$ from (3) by substituting $r=\tilde{E} u$ to obtain

$$
\begin{aligned}
S=E \int_{x_{r}}^{\infty} & f(x \mid \theta)\left((u(x, \theta)-\tilde{E} u)(1-\rho(1-F))^{n-1}\right. \\
& \left.+\int_{x_{r}}^{x}(u(x, \theta)-B(y))(n-1)(1-\rho(1-F(y \mid \theta)))^{n-2} \rho f(y \mid \theta) d y\right) d x .
\end{aligned}
$$

To establish (4), it suffices to show that $\left.\frac{d x_{r}}{d \rho}\right|_{S=s}<0$.

$$
\left.\frac{\partial S}{\partial x_{r}}\right|_{\rho=0}=-\left.E(1-F) \frac{\partial \tilde{E} u}{\partial x_{r}}\right|_{\rho=0}<0 .
$$

Since $\left.\frac{\partial S}{\partial x_{r}}\right|_{\rho=Q}<0$, it suffices to show that $\left.\frac{\partial S}{\partial \rho}\right|_{\rho=0}<0$.

$$
\begin{aligned}
\left.\frac{\partial S}{\partial \rho}\right|_{\rho=0} & =E \int_{x_{r}} f(x \mid \theta)\left[-(u(x, \theta)-\tilde{E} u)(n-1)(1-F)-\left.\frac{\partial \tilde{E} u}{\partial \rho}\right|_{\rho=0}\right. \\
& \left.+\int_{x_{r}}^{x}[u(x, \theta)-B(y)](n-1) f(y \mid \theta) d y\right] d x \\
= & (n-1) \tilde{E} u E(1-F)^{2}-\left.\left.E(1-F) \frac{\left.\partial \tilde{E} u\right|_{\rho=0}-(n-1) E \int_{x_{r}}^{\infty} f(x \mid \theta) u(x, \theta)(1-F) d x}{\partial \rho}\right|^{\infty}\right|_{x_{r}}(1-F(x \mid \theta))[u(x, \theta)-B(x)](n-1) f(x \mid \theta) d x \\
& =(n-1)\left[\left[E(1-F)^{2}\right] \tilde{E} u+[E(1-F)] \tilde{E} u(1-F)-\tilde{E} u \tilde{E}(1-F)\right) \\
& \left.+E \int_{x_{r}}^{\infty}[(F-F(x \mid \theta)) u(x, \theta)-(1-F(x \mid \theta)) B(x)] f(x \mid \theta) d x\right] \\
& =(n-1)\left[\frac{E(1-F)^{2} E u f}{E f}+\frac{E(1-F) E u(1-F) f}{E f}-\frac{E(1-F) E u f E(1-F) f}{(E f)^{2}}\right. \\
& \left.+E \int_{x_{r}}^{\infty}[(F-F(x \mid \theta)) u(x, \theta)-(1-F(x \mid \theta)) B(x)] f(x \mid \theta) d x\right] \equiv(n-1) \varphi(x) .
\end{aligned}
$$


Note that $\varphi(\infty)=0$. Thus, to show that $\left.\frac{\partial S}{\partial \rho}\right|_{\rho=0}<0$, it suffices to show that $\varphi^{\prime}\left(x_{r}\right) \geq 0$ for all $x_{r}$.

$$
\begin{aligned}
& \varphi^{\prime}\left(x_{r}\right)=\frac{\partial}{\partial x_{r}}\left[\frac{E(1-F)^{2} E u f}{E f}+\frac{E(1-F) E u(1-F) f}{E f}-\frac{E(1-F) E u f E(1-F) f}{(E f)^{2}}\right] \\
& +E f(1-F) B\left(x_{r}\right)+E \int_{x_{r}}^{\infty} f(x \mid \theta) f u(x, \theta) d x \\
& \geq \frac{\partial}{\partial x_{r}}\left[\frac{E(1-F)^{2} E u f}{E f}+\frac{E(1-F) E u(1-F) f}{E f}-\frac{E(1-F) E u f E(1-F) f}{(E f)^{2}}\right] \\
& +E f(1-F) \frac{E u f^{2}}{E f^{2}}+E(1-F) f u \\
& =-2 \frac{E(1-F) f}{E f} E u f-\frac{E(1-F)^{2}}{(E f)^{2}} E f_{x} E u f+\frac{E(1-F)^{2}}{E f} E u_{x} f+E u f_{x]} \\
& -\frac{E(1-F) E u(1-F) f}{(E f)^{2}} E f_{x}+\frac{E(1-F)}{E f}\left[E u_{x}(1-F) f-E u f^{2}+E u(1-F) f_{x]}-E(1-F) f u\right. \\
& +\frac{E u f E(1-F) f}{E f}+2 \frac{E(1-F) E u f E(1-F) f E f_{x}}{(E f)^{3}}+\frac{E f(1-F) E u f^{2}}{E f^{2}}+E(1-F) f u \\
& -\frac{E(1-F)}{(E f)^{2}} E u_{x} f E(1-F) f+E f_{x} u E(1-F) f-E u f E f^{2}+E u f E(1-F) f_{x]} \\
& =-\frac{E(1-F) f}{E f} E u f-\frac{E(1-F)^{2}}{(E f)^{2}} E f_{x} E u f+\frac{E(1-F)^{2}}{E f} E u_{x} f+E u f_{x]} \\
& -\frac{E(1-F) E u(1-F) f}{(E f)^{2}} E f_{x}+\frac{E(1-F)}{E f}\left[E u_{x}(1-F) f-E u f^{2}+E u(1-F) f_{x]}\right. \\
& +2 \frac{E(1-F) E u f E(1-F) f E f_{x}}{(E f)^{3}}+\frac{E f(1-F) E u f^{2}}{E f^{2}} \\
& -\frac{E(1-F)}{(E f)^{2}} E u_{x} f E(1-F) f+E f_{x} u E(1-F) f-E u f E f^{2}+E u f E(1-F) f_{x]} \\
& =\frac{E(1-F)^{2} E u_{x} f}{E f}-\frac{E(1-F) E(1-F) f E u_{x} f}{(E f)^{2}}+\frac{E(1-F) E u_{x}(1-F) f}{E f} \\
& +\frac{E u f^{2} E(1-F) f}{E f^{2}}-\frac{E u f E(1-F) f}{E f}-\frac{E u f^{2} E(1-F)}{E f}+\frac{E u f E(1-F) E f^{2}}{(E f)^{2}} \\
& +\frac{E(1-F)^{2} E u f_{x}}{E f}-\frac{E(1-F)^{2} E u f E f_{x}}{(E f)^{2}}-\frac{E(1-F) E(1-F) f E u f_{x}}{(E f)^{2}}+\frac{E(1-F) E(1-F) f E u f E f_{x}}{(E f)^{3}} \\
& +E(1-F)\left[\frac{E(1-F) u f_{x}}{E f}-\frac{E(1-F) f_{x} E u f}{(E f)^{2}}-\frac{E(1-F) u f E f_{x}}{(E f)^{2}}+\frac{E(1-F) f E u f E f_{x}}{(E f)^{3}}\right]
\end{aligned}
$$




$$
\begin{aligned}
& =\left[\frac{E(1-F)^{2}}{E f}-\frac{E(1-F) E(1-F) f}{(E f)^{2}}\right] E u_{x} f+\frac{E(1-F) E u_{x}(1-F) f}{E f} \\
& +\left[\frac{E u f^{2}}{E f^{2}}-\frac{E u f}{E f}\right]\left[E(1-F) f-\frac{E(1-F) E f^{2}}{E f}\right] \\
& \left.+\left[E(1-F)^{2}-\frac{E(1-F) E(1-F) f}{E f}\right] \tilde{E} u \frac{f_{x}}{f}-\tilde{E} u \tilde{E} \frac{f_{x}}{f}\right] \\
& +E(1-F) \tilde{E}\left[(1-F)(u-\tilde{E} u)\left(\frac{f_{x}}{f}-\tilde{E} \frac{f_{x}}{f}\right)\right] \geq 0 .
\end{aligned}
$$

The first line is positive by lemma $\mathrm{A}$, the second since

$$
\frac{E u f^{2}}{E f} \geq \frac{E u f}{E f} \frac{E f^{2}}{E f}
$$

and the second part of lemma A. The third is positive by lemma A and the fact that $u$ and $\frac{f_{x}}{f}$ are increasing by affiliation. That the fourth is positive requires an argument. The fourth term comes in the form $E \alpha \beta \gamma$, where $\alpha, \beta, \gamma$ are all increasing, $\alpha>0$, and $E \beta=E \gamma=0$. Define an expectation

$$
E^{\prime}(\quad)=\frac{E \alpha()}{E \alpha} \text {. Then } E \alpha \beta \gamma=E \alpha E^{\prime} \beta \gamma \geq E \alpha E^{\prime} \beta E^{\prime} \gamma=\frac{E \alpha \beta E \alpha \gamma}{E \alpha} \geq \frac{E \alpha E \beta E \alpha E \gamma}{E \alpha}=0
$$

This shows the fourth term is positive, as desired. Thus $\varphi^{\prime}\left(x_{r}\right)>0$, and

$$
\left.\frac{\partial S}{\partial \rho}\right|_{\rho=0}=(n-1) \varphi\left(x_{r}\right)=-(n-1) \int_{x_{r}}^{\infty} \varphi^{\prime}(x) d x<0 .
$$

\section{Sufficient Condition for (4):}

Assuming stability implies that $\partial S / \partial \rho<0$, it is sufficient to prove that $\partial S / \partial x_{r}<0$. As before, we suppress the arguments $\left(x_{r} \mid \theta\right)$ and $\left(x_{r}, \theta\right)$. Using (2) and (A1),

$$
\frac{\partial S}{\partial x_{r}}=E_{\theta}\left[(1-\rho(1-F))^{n-1} f\right]\left[(n-1) \rho\left(B\left(x_{r}\right)-\tilde{E} u\right) \tilde{E}\left(\frac{1-F}{1-\rho(1-F)}\right)-\tilde{E}\left(\frac{1-F}{f}\right)\left(\frac{\partial \tilde{E} u}{\partial x_{r}}\right)\right]
$$

Thus, $\frac{\partial S}{\partial x_{r}}<0$ if and only if

$\left.\left.\left.0<\tilde{E} \frac{1-F}{f}\right] \tilde{E} u_{x}+\tilde{E}\left(u \frac{f_{x}}{f}\right)-\tilde{E} u \tilde{E} \frac{f_{x}}{f}\right]+(n-1) \rho\left(B\left(x_{r}\right)-\tilde{E} u\right) \tilde{E} \frac{1-F}{f} \tilde{E} \frac{f}{1-\rho(1-F)}-\tilde{E} \frac{1-F}{1-\rho(1-F)}\right]$

Since $u_{x}$ is nonnegative, we may drop it. The resulting sufficient condition becomes

$$
\left.\left.0<\tilde{E} \frac{1-F}{f}\right]\left[\tilde{E}\left(u \frac{f_{x}}{f}\right)-\tilde{E} u \tilde{E} \frac{f_{x}}{f}\right]+(n-1) \rho\left(B\left(x_{r}\right)-\tilde{E} u\right) \tilde{E} \frac{1-F}{f} \tilde{E} \frac{f}{1-\rho(1-F)}-\tilde{E} \frac{1-F}{1-\rho(1-F)}\right]
$$


Since (A2) is linear in $u$, (A2) holds if and only if (A2) holds for a basis of $u$. A convenient basis is the indicator functions, $u=1$ if $\theta \geq \theta^{*}$, and 0 otherwise. Thus, a sufficient condition for (4) (when combined with stability) is that, for all $\theta^{*}$,

$$
\left.\tilde{E}\left[\frac{f_{x}}{f} \mid \theta \geq \theta^{*}\right]-\tilde{E}\left[\frac{f_{x}}{f}\right]+(n-1) \rho\left[1-\frac{\tilde{E} \frac{1-F}{1-\rho(1-F)}}{\tilde{E} \frac{1-F}{f} \tilde{E} \frac{f}{1-\rho(1-F)}}\right] \tilde{E}\left(\frac{f}{1-\rho(1-F)} \mid \theta \geq \theta^{*}\right)-\tilde{E} \frac{f}{1-\rho(1-F)}\right] \geq 0 .
$$

This condition is also necessary for (4) to hold for all nondecreasing $u$.

Proof of Lemma 3: Equation (6) is a routine computation from (5) using (2). We show (7) for the case of second price auctions. The argument foran oral auction is similar but more tedious. McAfee and Vincent (1992) show the result for first price auctions. First integrate (3) by parts to obtain:

(A3) $s=E_{\theta}\left(1-F\left(x_{r} \mid \theta\right)\right)\left(u\left(x_{r}, \theta\right)-r\right)\left(1-\rho\left(1-F\left(x_{r} \mid \theta\right)\right)\right)^{n-1}$

$$
\begin{aligned}
& +\int_{x_{r}}^{\infty}(1-F(x \mid \theta)) u_{x}(x, \theta)(1-\rho(1-F(x \mid \theta)))^{n-1} d x \\
& +\int(1-F(x \mid \theta))(u(x, \theta)-B(x))(n-1)(1-\rho(1-F(x \mid \theta)))^{n-2} \rho f(x \mid \theta) d x_{j} .
\end{aligned}
$$

Define $\hat{E}_{x}(\bullet)^{x_{r}}=\frac{\left.E_{\theta[}(\bullet)(1-\rho(1-F(x \mid \theta)))^{n-2} f(x \mid \theta)^{2}\right]}{\left.E_{\theta I}(1-\rho(1-F(x \mid \theta)))^{n-2} f(x \mid \theta)^{2}\right]}$.

$$
\begin{aligned}
& E_{\theta}\left[(1-F(x \mid \theta))(u(x, \theta)-B(x))(n-1)(1-\rho(1-F(x \mid \theta)))^{n-2} f(x \mid \theta)\right] \\
& =\hat{E}_{x}\left[\frac{1-F(x \mid \theta)}{f(x \mid \theta)}(u(x, \theta)-B(x))\right] E_{\theta}\left[(1-\rho(1-F(x \mid \theta)))^{n-2} f(x \mid \theta)^{2}\right] \\
& \geq \hat{E}_{x}\left[\frac{1-F(x \mid \theta)}{f(x \mid \theta)}\right] \hat{E}_{x}(u(x, \theta)-B(x))_{]} E_{\theta}\left[(1-\rho(1-F(x \mid \theta)))^{n-2} f(x \mid \theta)^{2}\right]=0 .
\end{aligned}
$$

Integrating (5) by parts,

$$
\begin{aligned}
\Psi= & \left.E_{\theta} \sigma(\theta)-(u(x, \theta)-\sigma(\theta))_{\left(1-(1-\rho(1-F(x \mid \theta)))^{n}\right)}\right)_{x_{r}}{ }_{x_{r}} \\
& \left.+\int_{x_{r}}^{\infty} u_{x}(x, \theta)_{(} 1-(1-\rho(1-F(x \mid \theta)))^{n}\right\rangle d x_{]}-n \rho s \\
= & \left.E_{\theta[} \sigma(\theta)+\left(u\left(x_{r}, \theta\right)-\sigma(\theta)\right)_{(} 1-\left(1-\rho\left(1-F\left(x_{r} \mid \theta\right)\right)\right)^{n}\right) \\
& +\int_{x_{r}}^{\infty} u_{x}(x, \theta)_{(} 1-(1-\rho(1-F(x \mid \theta)))^{n}{ }_{\rangle} d x_{]}-n \rho s .
\end{aligned}
$$




$$
\begin{aligned}
& \frac{\partial \Psi}{\partial \rho}=n E_{\theta \mid}\left(u\left(x_{r}, \theta\right)-\sigma(\theta)\right)\left(1-F\left(x_{r} \mid \theta\right)\right)\left(1-\rho\left(1-F\left(x_{r} \mid \theta\right)\right)\right)^{n-1} \\
& +\int_{x_{r}}^{\infty} u_{x}(x, \theta)(1-\rho(1-F(x \mid \theta)))^{n-1}(1-F(x \mid \theta)) d x-s_{]} \\
& \text {(A3) } \\
& =n E_{\theta[}(r-\sigma(\theta))\left(1-F\left(x_{r} \mid \theta\right)\right)\left(1-\rho\left(1-F\left(x_{r} \mid \theta\right)\right)\right)^{n-1} \\
& \begin{array}{ll} 
& -\int_{x_{r}}^{\infty}(1-F(x \mid \theta))(u(x, \theta)-B(x))(n-1)(1-\rho(1-F(x \mid \theta)))^{n-2} \rho f(x \mid \theta) d x_{]} \\
(A 4) & n E_{\theta}\left[(r-\sigma(\theta))\left(1-F\left(x_{r} \mid \theta\right)\right)\left(1-\rho\left(1-F\left(x_{r} \mid \theta\right)\right)\right)^{n-1}\right] .
\end{array}
\end{aligned}
$$

Proof of Theorem 4: First note that

$$
\begin{aligned}
& \frac{E_{\theta}\left[\sigma(\theta)\left(1-\rho\left(1-F\left(x_{r} \mid \theta\right)\right)\right)^{n-1}\left(1-F\left(x_{r} \mid \theta\right)\right)\right]}{E_{\theta}\left[\left(1-\rho\left(1-F\left(x_{r} \mid \theta\right)\right)\right)^{n-1}\left(1-F\left(x_{r} \mid \theta\right)\right)\right]} \\
& =\frac{\left.E_{\theta}\left[\sigma(\theta) \frac{1-F\left(x_{r} \mid \theta\right)}{f\left(x_{r} \mid \theta\right)}\left(1-\rho\left(1-F\left(x_{r} \mid \theta\right)\right)\right)^{n-1} f\left(x_{r} \mid \theta\right)\right)\right]}{E_{\theta}\left[\left(1-\rho\left(1-F\left(x_{r} \mid \theta\right)\right)\right)^{n-1} f\left(x_{r} \mid \theta\right)\right]} \times \frac{E_{\theta}\left[\left(1-\rho\left(1-F\left(x_{r} \mid \theta\right)\right)\right)^{n-1} f\left(x_{r} \mid \theta\right)\right]}{E_{\theta}\left[\left(1-\rho\left(1-F\left(x_{r} \mid \theta\right)\right)\right)^{n-1}\left(1-F\left(x_{r} \mid \theta\right)\right)\right]} \\
& =\tilde{E}\left[\sigma(\theta) \frac{1-F\left(x_{r} \mid \theta\right)}{f\left(x_{r} \mid \theta\right)}\right] \times \frac{E_{\theta}\left[\left(1-\rho\left(1-F\left(x_{r} \mid \theta\right)\right)\right)^{n-1} f\left(x_{r} \mid \theta\right)\right]}{E_{\theta}\left[\left(1-\rho\left(1-F\left(x_{r} \mid \theta\right)\right)\right)^{n-1}\left(1-F\left(x_{r} \mid \theta\right)\right)\right]} \\
& \geq \tilde{E}_{[} \sigma(\theta)_{]} \tilde{E}\left[\frac{1-F\left(x_{r} \mid \theta\right)}{f\left(x_{r} \mid \theta\right)}\right] \times \frac{E_{\theta}\left[\left(1-\rho\left(1-F\left(x_{r} \mid \theta\right)\right)\right)^{n-1} f\left(x_{r} \mid \theta\right)\right]}{E_{\theta}\left[\left(1-\rho\left(1-F\left(x_{r} \mid \theta\right)\right)\right)^{n-1}\left(1-F\left(x_{r} \mid \theta\right)\right)\right]}=\tilde{E}[\sigma(\theta)] .
\end{aligned}
$$

Thus, using (4) and Lemma 3,

$$
\begin{aligned}
\frac{d \Psi}{d r}= & \frac{\partial \Psi}{\partial x_{r}} \frac{d x_{r}}{d r}+\frac{\partial \Psi}{\partial \rho} \frac{d \rho}{d r} \\
\geq & \frac{d x_{r}}{d r} E_{\theta}\left[(\sigma(\theta)-r) n\left(1-\rho\left(1-F\left(x_{r} \mid \theta\right)\right)\right)^{n-1} \rho f\left(x_{r} \mid \theta\right)\right] \\
& +\frac{d \rho}{d r} E_{\theta}\left[(r-\sigma(\theta)) n\left(1-\rho\left(1-F\left(x_{r} \mid \theta\right)\right)\right)^{n-1}\left(1-F\left(x_{r} \mid \theta\right)\right)\right] \\
= & \frac{d x_{r}}{d r} \tilde{E}[(\sigma(\theta)-r)] E_{\theta}\left[n\left(1-\rho\left(1-F\left(x_{r} \mid \theta\right)\right)\right)^{n-1} \rho f\left(x_{r} \mid \theta\right)\right]
\end{aligned}
$$




$$
\begin{aligned}
& \quad+\left(-\frac{d \rho}{d r}\right) E_{\theta}\left[(\sigma(\theta)-r) n\left(1-\rho\left(1-F\left(x_{r} \mid \theta\right)\right)\right)^{n-1}\left(1-F\left(x_{r} \mid \theta\right)\right)\right] \\
& \geq \frac{d x_{r}}{d r} \tilde{E}[(\sigma(\theta)-r)] E_{\theta}\left[n\left(1-\rho\left(1-F\left(x_{r} \mid \theta\right)\right)\right)^{n-1} \rho f\left(x_{r} \mid \theta\right)\right] \\
& \quad+\left(-\frac{d \rho}{d r}\right) \tilde{E}[(\sigma(\theta)-r)] E_{\theta}\left[n\left(1-\rho\left(1-F\left(x_{r} \mid \theta\right)\right)\right)^{n-1}\left(1-F\left(x_{r} \mid \theta\right)\right)\right]
\end{aligned}
$$

Thus $\tilde{E}[\sigma(\theta)-r]>0 \Rightarrow \frac{d \Psi}{d r} \geq 0$. Since $\tilde{E}[\sigma(\theta)]$ is increasing in $x_{r}$ and decreasing in $\rho, \tilde{E}[\sigma(\theta)]$ is increasing in $r$. Thus, increasing $r$ from $r_{0}$ to $\sigma_{0}$ leaves $\mathrm{d} \Psi / \mathrm{d} r>0$.

\section{Proof of Lemma 5:}

$$
\begin{aligned}
& \frac{E_{\theta}\left[\sigma(\theta)\left(1-\rho\left(1-F\left(x_{r} \mid \theta\right)\right)\right)^{n-1} f\left(x_{r} \mid \theta\right)\right]}{E_{\theta}\left[\left(1-\rho\left(1-F\left(x_{r} \mid \theta\right)\right)\right)^{n-1} f\left(x_{r} \mid \theta\right)\right]} \\
& =\frac{E_{\theta}\left[\sigma(\theta) \frac{f\left(x_{r} \mid \theta\right)}{1-\rho\left(1-F\left(x_{r} \mid \theta\right)\right)}\left(1-\rho\left(1-F\left(x_{r} \mid \theta\right)\right)\right)^{n}\right]}{E_{\theta}\left[\left(1-\rho\left(1-F\left(x_{r} \mid \theta\right)\right)\right)^{n}\right]} \times \frac{E_{\theta}\left[\left(1-\rho\left(1-F\left(x_{r} \mid \theta\right)\right)\right)^{n}\right]}{E_{\theta}\left[\left(1-\rho\left(1-F\left(x_{r} \mid \theta\right)\right)\right)^{n-1} f\left(x_{r} \mid \theta\right)\right]} \\
& \geq \frac{E_{\theta}\left[\sigma(\theta)(1-\rho(1-F(x \mid \theta)))^{n}\right]}{E_{\theta}\left[(1-\rho(1-F(x \mid \theta)))^{n}\right]} \frac{E_{\theta}\left[\frac{f\left(x_{r} \mid \theta\right)\left(1-\rho\left(1-F\left(x_{r} \mid \theta\right)\right)\right)^{n}}{1-\rho\left(1-F\left(x_{r} \mid \theta\right)\right)}\right]}{E_{\theta}\left[\left(1-\rho\left(1-F\left(x_{r} \mid \theta\right)\right)\right)^{n}\right]} \frac{E_{\theta}\left[\left(1-\rho\left(1-F\left(x_{r} \mid \theta\right)\right)\right)^{n}\right]}{E_{\theta}\left[\left(1-\rho\left(1-F\left(x_{r} \mid \theta\right)\right)\right)^{n-1} f\left(x_{r} \mid \theta\right)\right]} \\
& =\frac{E_{\theta}\left[\sigma(\theta)(1-\rho(1-F(x \mid \theta)))^{n}\right]}{E_{\theta}\left[(1-\rho(1-F(x \mid \theta)))^{n}\right]} .
\end{aligned}
$$




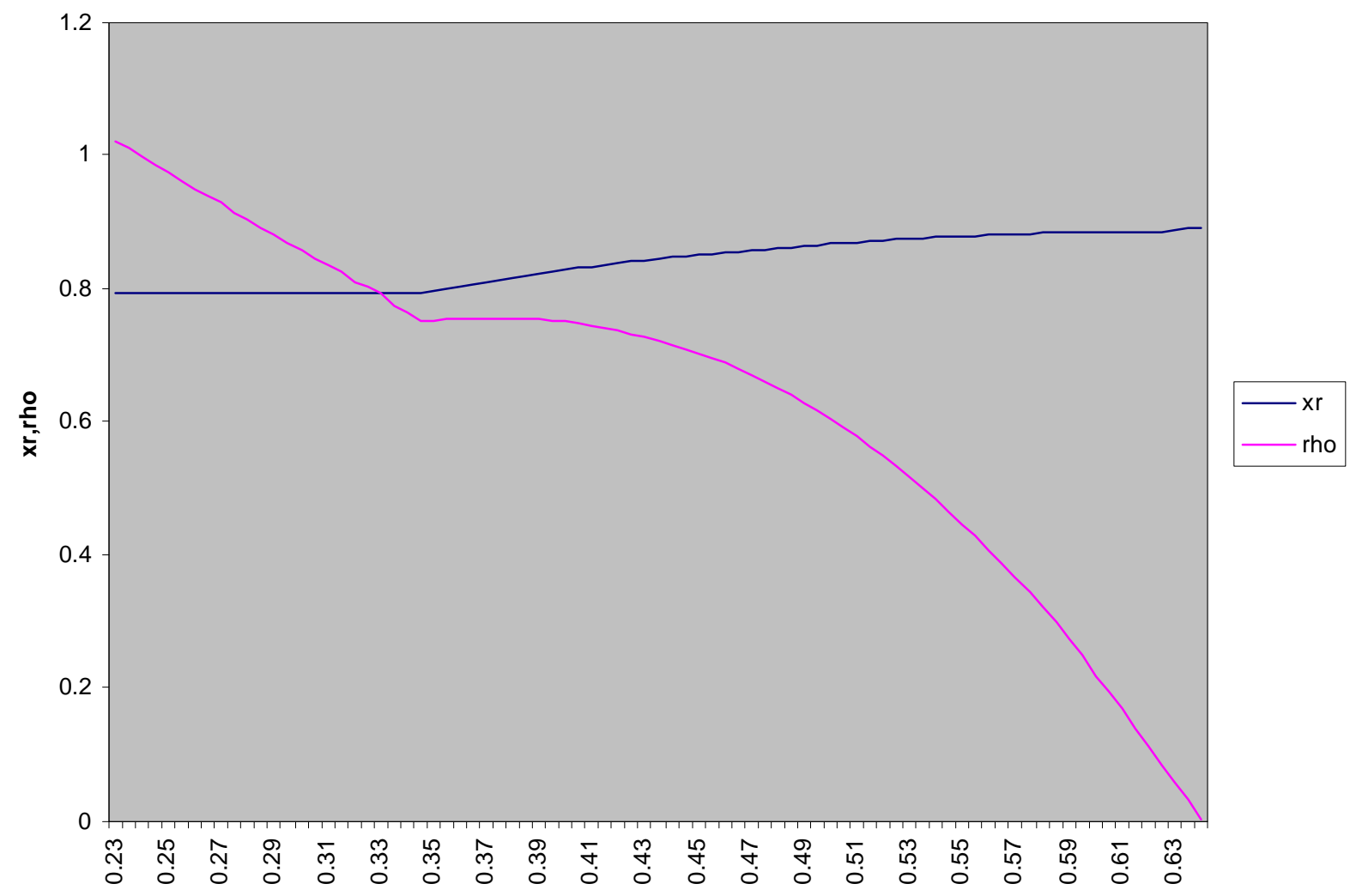

Figure 1-An example of non-monotonicity of $\rho$. 


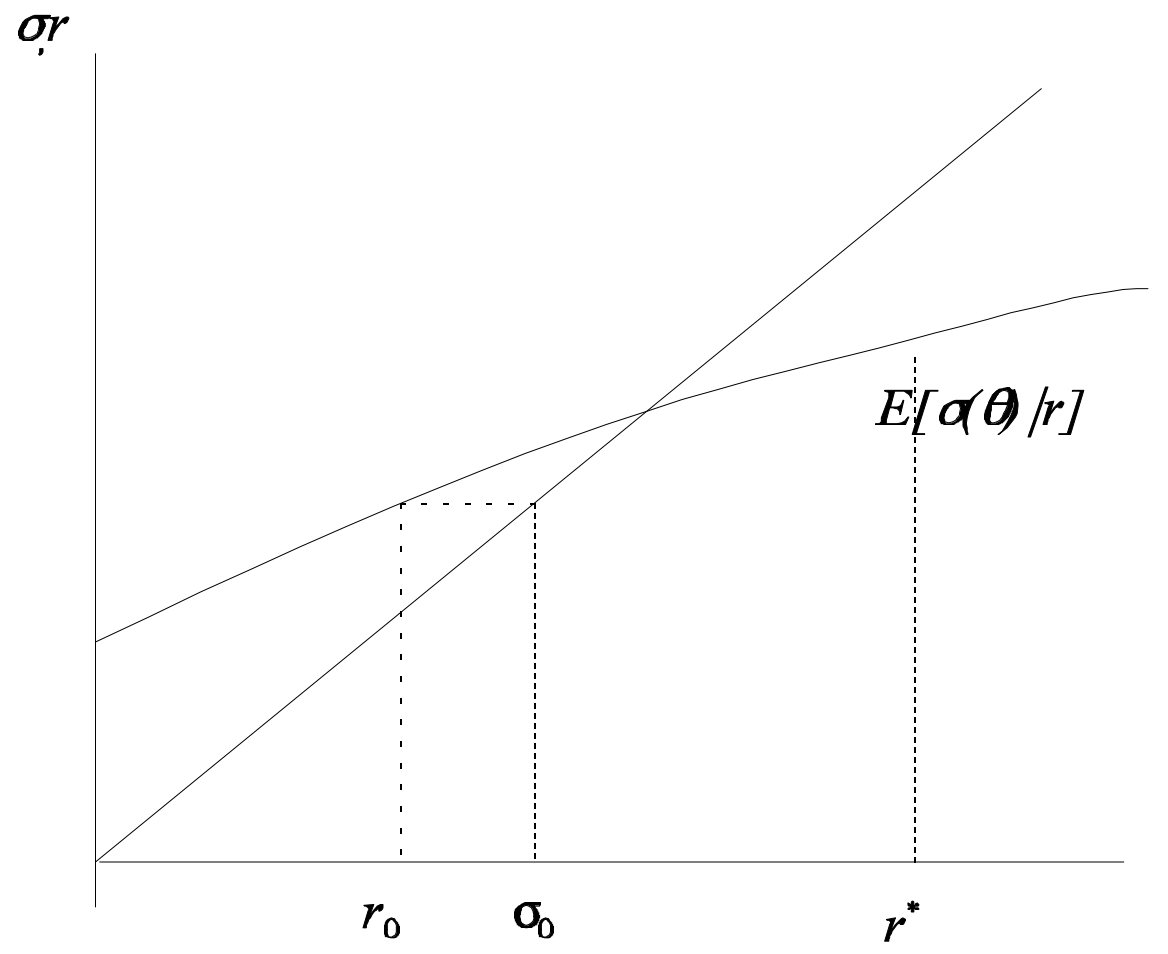

Figure 2: An illustration of Theorem 4. Given an initial reserve $r$ and a realized $\sigma_{0}$, the reserve should be raised to at least $\sigma_{\sigma_{0}}$. Note that the optimal reserve, $\boldsymbol{r}^{*}$, exceeds the solution to $r=\tilde{E}[\sigma(\theta) \mid r]$. 


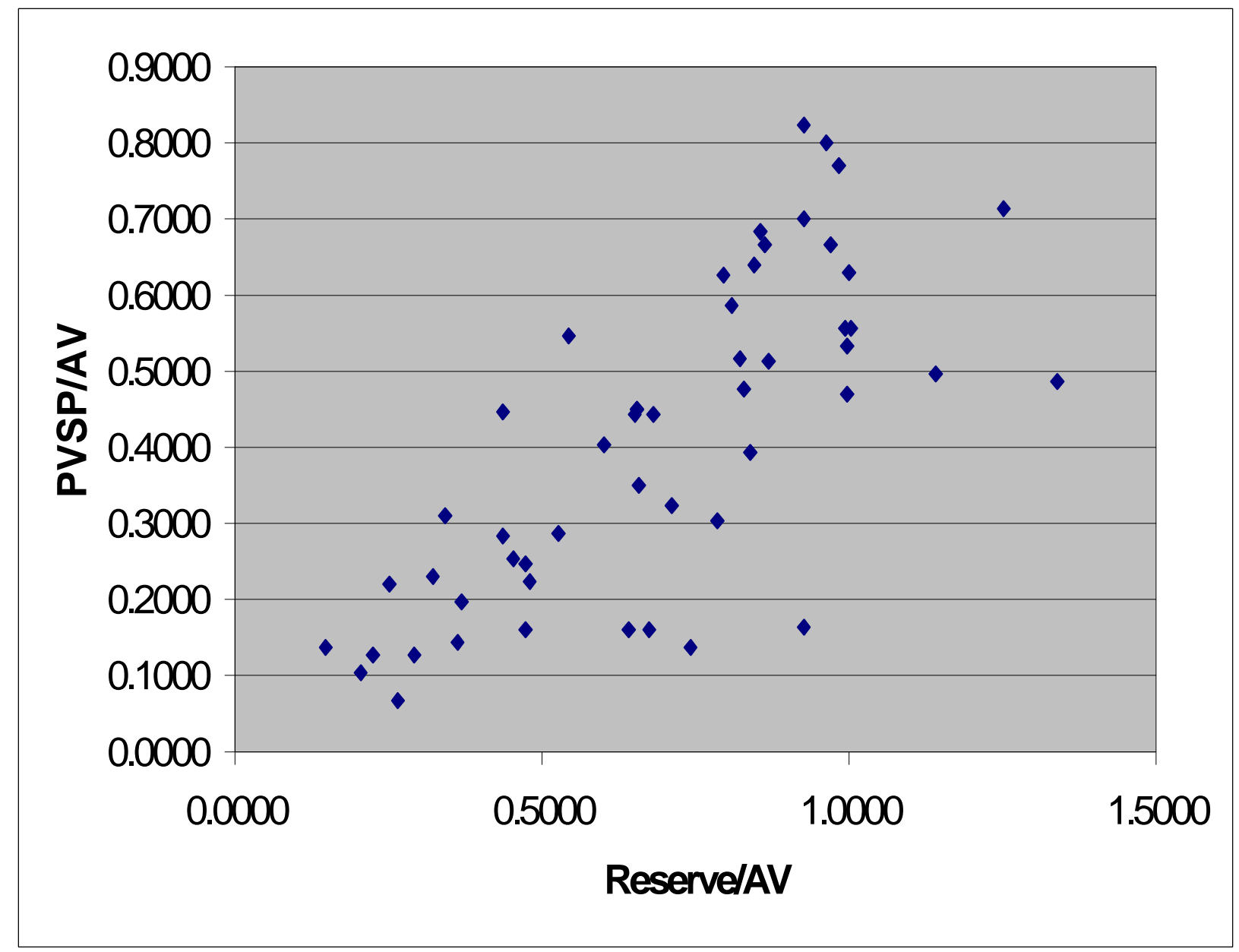

Figure 3-Scatter plot of PVSP/AV versus Reserve/AV in Private Auction 